Journal Article

\title{
Aerodynamic Analysis and Design of a Rim-Driven Fan for Fast Flight
}

Bolam, R. C., Vagapov, Y., Day, R. J., \& Anuchin, A

This article is published by American Institute of Aeronautics and Astronautics. The definitive version of this article is available at: https://arc.aiaa.org/journal/jpp

\section{Recommended citation:}

Bolam, R. C., Vagapov, Y., Day, R. J., \& Anuchin, A (2020) 'Aerodynamic Analysis and Design of a Rim-Driven Fan for Fast Flight', Journal of Propulsion and Power, published online 29 Dec 2020. doi: 10.2514/1.B37736 


\title{
Aerodynamic Analysis and Design of a Rim Driven Fan for Fast Flight
}

\author{
Robert C. Bolam, ${ }^{1}$ Yuriy Vagapov ${ }^{2}$ and Richard J. Day ${ }^{3}$ \\ Glyndwr University, Wrexham, LL11 2AW, UK \\ and \\ Alecksey Anuchin ${ }^{4}$ \\ Moscow Power Engineering Institute, Moscow, 111250, Russia
}

\begin{abstract}
This paper discusses the aerodynamic analysis and design of a novel, hub-less, contrarotating, Rim Driven Fan (RDF) device. Rim Driven Thruster technology has been utilized for marine propulsion for decades, yet RDF technology has not been comparably developed for aerospace applications. This paper demonstrates that an innovative two stage contra-rotating RDF configuration provides the potential for a significant increase in the available thrust and efflux velocity when compared to existing technologies. The analysis was conducted for an RDF device with a relatively small fan diameter of $120 \mathrm{~mm}$. However, the findings of this study can be equally applied to the performance of much larger and more powerful RDF propulsion units. This would also include devices having multiple contra-rotating paired stages, for example; four, six or more rotors to permit higher-pressure ratios and exhaust airspeeds suitable for large modern aircraft propulsion.
\end{abstract}

\section{Nomenclature}

$\vec{A}_{j} \quad=$ the $j$ face area vector, $\mathrm{m}^{2}$

$\alpha=$ absolute air-velocity vector direction, Degrees

$\beta=$ relative air-velocity vector direction, Degrees

$c \quad=$ chord (of fan blade), $\mathrm{m}$

\footnotetext{
${ }^{1}$ Senior Lecturer, Faculty of Art, Science and Technology.

${ }^{2}$ Reader, Faculty of Art, Science and Technology.

${ }^{3}$ Professor, Faculty of Art, Science and Technology.

${ }^{4}$ Head of Department, Department of Electric Drives.
} 


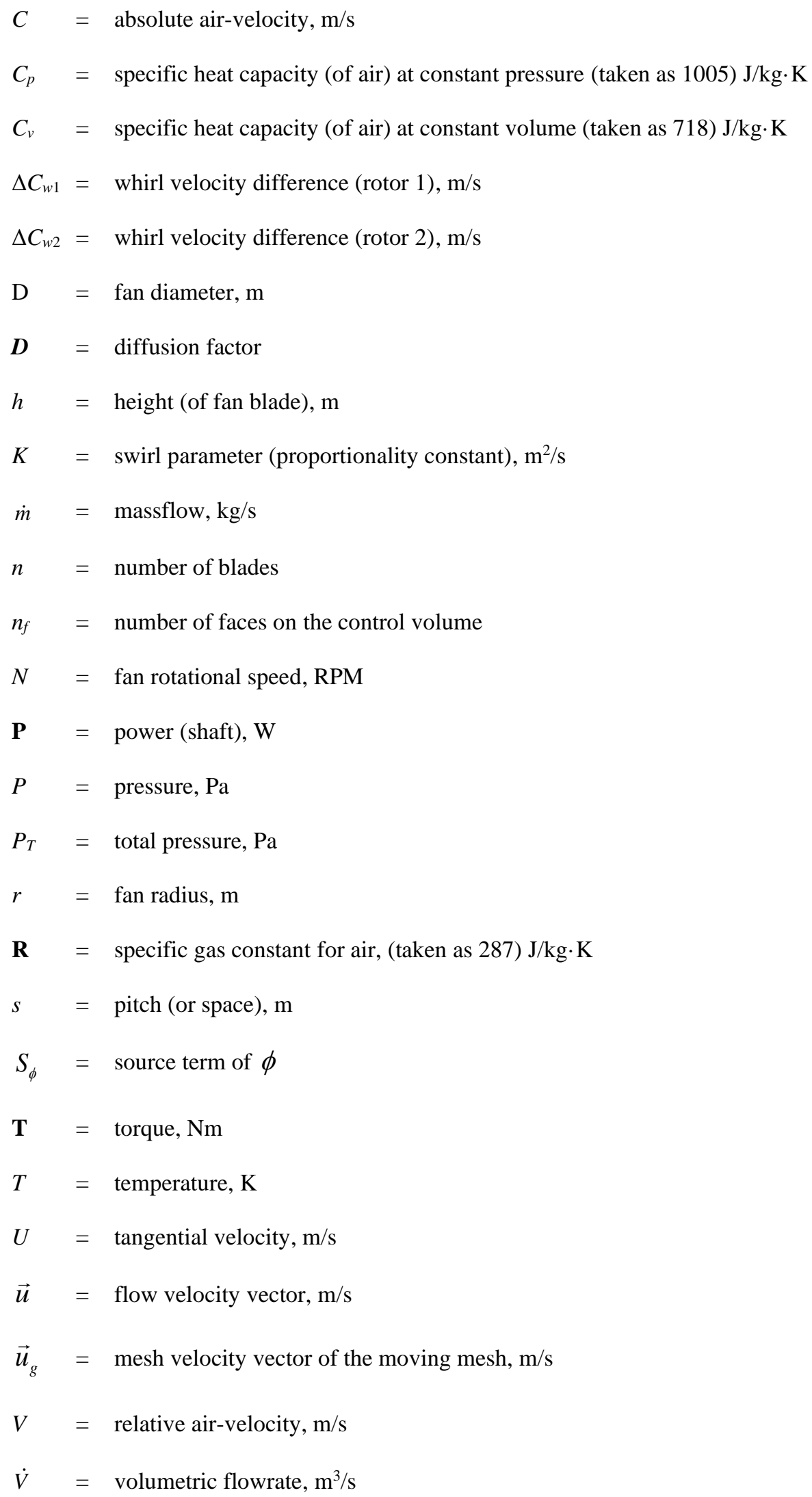




\section{Superscripts \\ $=$ air angle}

\section{Introduction}

$\mathrm{C}^{\text {LECTRICAL propulsion heralds an exciting era in aeronautical engineering and seems destined to play a critical }}$ role in protecting our environment and energy supply by reducing aircraft emissions. It has been identified as a key priority in world-wide international governmental efforts to tackle climate change with the goal being zero emission flight accompanied by zero reduction in operational capabilities [1]. Although this may appear a distant aspiration, the tasks associated with overcoming the technical problems are already well underway and one of the major challenges that has arisen is how to achieve efficient high-speed flight using electrical motor technology. Currently the world's major civil airframe, systems and powerplant manufacturers are taking similar approaches to achieve subsonic commercial airspeeds and these all are based on hub-driven Electric Ducted Fan (EDF) technology [2]. Various research programs are currently underway with one international consortium aiming to develop a 2 MW electrically powered single rotor EDF that is conventionally mounted on a regional jet airframe. Whilst another major consortium has plans to develop a family of hybrid-electric regional aircraft based on conventional airframe configurations with rear mounted EDF units [3]. It is, however, widely acknowledged that, large centralized EDF propulsion and conventional aircraft wing and tube designs are likely to present electrical supply and aerodynamic inefficiencies that would penalize the overall performance of an electrically powered aircraft $[4,5]$. This is particularly evident if these conventional designs are assessed alongside the possible benefits that electrical propulsion has to offer; namely blended wing body and distributed thrust architectures [6,7]. Small EDF units allow distributed thrust designs to be implemented, but their utilization is limited to low-speed flight applications, such as those of general aviation and small unmanned aircraft [8]. This is because small single-stage rotors require prohibitively high rotational speeds to achieve high exhaust airspeeds owing to their hub-driven configuration. However, a promising solution appears in the form of Rim Driven Fan (RDF) technology which offers an alternative motor architecture with the potential for high thrust and exhaust air speeds to be achieved whilst maintaining relatively small fan inlet diameters [9]. This paper presents a performance analysis conducted on an RDF design with a relatively small fan diameter of $120 \mathrm{~mm}$.

It has long been established that contra-rotating (a.k.a. counter-rotating) propellers and fans offer performance improvements over single stage equivalents. As far back as 1944 "Dual Rotation" was described as the most recent development in modern propeller design [10] and highlighted for its "efficient operation in thin atmosphere at great 
heights". The relative ease with which contra-rotating propeller technology can be applied to electrical aircraft propulsion has been realized with twin axial flux motors driving contra-rotating shaft assemblies [11]. Open-fan, Open-rotor or Prop-fan designs can also feature contra-rotation and have been the subject of analysis and prototype testing by Chen and Williams in the 1980's [12] and more recently by Brouckaert, et al. [13]. In their paper on the performance prediction of contra-rotating rotors, Guerin et al. [14], highlight the limitations of large diameter single stage ducted fans and consider an open rotor architecture to be a preferable alternative. Their performance evaluations, based on a computerized model, predict a $10 \%$ gain in Specific Fuel Consumption (SFC) as a benefit over an equivalent ducted fan design. However, this study concluded that the high levels of acoustic noise generated by open rotor architectures remain a disadvantage. A study by Eichenberg et al. [15] into a conceptual design of a hub-less 32inch diameter levitated ducted fan concentrated solely on the electromagnetic architecture of a single rotor rim driven fan device and unfortunately did not consider the aerodynamic analysis of the hub-less fan. Ducted fans or propellers offer improved efficiency as they reduce the tip losses associated with open rotor designs [16], which is a significant reason why contra-rotating ducted fan technology is attracting increased attention for aerospace vehicle applications, such as the powering of small vertical take-off and landing (VTOL), unmanned and autonomous aerial vehicles. A recent study by Nemnem et al. [17], considered the analysis of a contra-rotating, hub-driven ducted fan capable of generating $40 \mathrm{~N}$ of thrust with a $20-\mathrm{cm}$ fan diameter and identified current ducted fan pressure ratios to be in a range of 1.02 to 1.16 . This study also highlighted that the higher rotor solidity ratio in a contra-rotating subsonic flow fan can provide increased pressure ratios and hence increased thrust, without the need for an increase in rotational speed or fan diameter. A velocity vector analysis is also provided in the study, representing both rotor stages and indicating how the wake of the second rotor can be directed towards the axial flow direction thus improving propulsive efficiency. However, the maximum relative velocity value, of the airflow across the second stage rotor, is not identified as a critical parameter with regard to maintaining a subsonic flow regime through the fan. Neither is a method developed to determine the magnitude of this critical $V_{3}$ parameter. This paper presents a velocity vector analysis conducted on an RDF design and develops a trigonometric expression to enable the magnitude of the critical inlet-air velocity at the second stage rotor to be calculated.

Hub-driven fans have the disadvantage of generating an annulus section airflow as the air passes around the central motor and hub assembly. This results in performance penalties due to the reduced cross-sectional flow areas for given duct inlet areas and increased frictional drag because of the increase in wetted surface area [18]. Flow imbalances 
across the plane of the air-flow annulus also contribute to reduced performance and have been the focus of analytical and experimental studies on low speed contra-rotating fans for aerospace propulsion applications, with simulated complex inflow distortions [19]. In these studies, total pressure co-efficient parameters were selected to provide an understanding of the pressure distribution and flow behavior through the stage. One key advantage of a RDF architecture is the ease by which contra-rotation and the ability to vary the speed ratios between the rotors can be implemented. Varying the speeds of the rotors offers the potential for an increased degree of flow control through the fan allowing its aerodynamic efficiency to be optimised [16]. Chen et al. [20] have numerically and experimentally investigated the performance of an axial flow hub driven contra-rotating compressor under differing combinations of rotational speeds. The outcome of which indicated that the rotor speed ratio (Rotor1/Rotor2) has a significant effect on the off-design rotor performance. With an increase in the ratio showing higher efficiencies and a decrease indicating a more stable stall free operating range. Tip section flow stability in this hub driven configuration was also identified as an area of concern. Clearly this may therefore be avoided with the implementation of rim driven fan technology. The rotor-rotor interactions within counter rotating compressors are coming under increased scrutiny as consideration is given to removal of the stator stages in conventional axial compressors to reduce engine mass [21]. In [22] Nouri et al. present a design and experimental evaluation of a ducted, counter-rotating, axial-flow fan system. Their study demonstrated very good agreement between numerical and experimental results, although it only focused on hubdriven fan aerodynamics for which the distance between rotors is relatively large when compared with an RDF configuration. A two-stage hub-driven contra-rotating fan arrangement has been the subject of a design and optimisation study in [23] which considers varied axial spacing of contra-rotating hub-driven fan rotors. This parametric study proposed a fan optimisation process and also involved varying the fan speed ratios. However, the results are applicable to relatively low rotational speeds and to fans having throughflow airspeeds and pressure-rises un-representative of high-speed aircraft propulsion applications. The literature search provided no evidence that aerodynamic analyses of hub-less RDF designs existed and that the available aerodynamic performance literature appears limited solely to hub-driven ducted fan architectures. It was therefore considered important to conduct such a hub-less RDF study. This paper provides an aerodynamic analysis of the contra-rotating fans of a small hub-less RDF device suitable for an Unmanned Aerial Vehicle (UAV) application (Fig. 1) in order to enhance and illuminate the existing literature in this field of study. The analyses associated with the mechanical installation of the fan, motor and bearing configurations, are considered beyond the scope of this study. 
All atmospheric propulsion mechanisms utilise one or more of the following three components: an intake or diffuser; a source of energy (actuator) and a propelling nozzle. For turbo-jet, turbo-fan and turbo-prop engines the source of energy is the section comprising the compressors, combustion chambers and turbines. In the case of piston engine aircraft, no diffuser or nozzle mechanisms are usually required and the energy source is the piston engine driving a propeller. For electrical propulsion mechanisms the source of energy is the electrical motor which is normally configured to drive a propeller, fan or compressor via a mechanical hub attachment. There is no definitive difference between a compressor and a fan although, fans are generally used in applications requiring high flow rates across low pressure differentials and compressors in applications involving higher-pressure differentials and significant increases in gas density. The study presented in this paper concentrates on the energy source (rim driven fan) part of the propulsion mechanism. It is intended that the performance of suitable intake (diffuser) and exhaust duct (propelling nozzle) configurations shall be the subjects of future analytical studies.

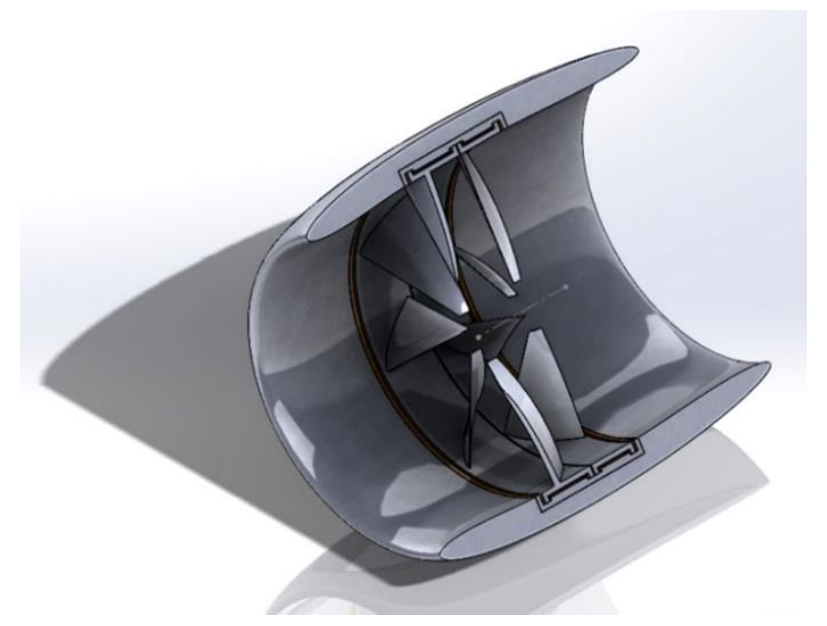

Fig. 1 Cutaway view of a Rim Driven Fan (RDF) concept model with contra-rotating fans.

Table 1 Modern Twin-spool turbofan performance parameters [24]

\begin{tabular}{lc}
\hline \hline Parameter & Value \\
\hline Fan Pressure Ratio & 1.65 \\
Compressor Pressure Ratio & 25.0 \\
Engine By-pass ratio (Fan massflow/Compressor massflow) & 5.0 \\
Fan and Compressor polytropic efficiency & 0.9 \\
Total Air Mass-flow & $215 \mathrm{~kg} / \mathrm{s}$ \\
\hline \hline
\end{tabular}

Nowadays the majority of sub-sonic commercial transport aircraft are powered by turbofan engines. Table 1 gives data for a modern twin-spool turbofan engine comprising of both an axial fan and a multi-stage axial compressor 
capable of propelling an aircraft to high subsonic speeds e.g. Mach of 0.7 to 0.85 . The tabulated data illustrates that the majority of the propulsive thrust for this type of engine is being developed across the fan which has a pressure ratio (Outlet stagnation pressure/Inlet stagnation pressure) of 1.65. It is a drag reduction priority of high-speed turbofan or turbojet engines to achieve a large flowrate per unit frontal area and this requires the optimisation of fan pressure ratios and the minimisation of any obstructions to the passage of the airflow. High fan mass-flow rates are a feature of turbofan engines with civil aircraft designs tending to use single-stage fans to minimise weight and noise. Turbofan engines commonly used in commercial aviation typically have fan pressure ratios ranging between 1.5 and 1.8 [16] thus enabling high subsonic aircraft speeds to be achieved. The compressor airflow is primarily used to support the combustion process and drive the turbines, although it also contributes to the overall thrust of the engine as it exhausts via the propelling nozzle. To achieve the optimum fan pressure ratio a combination of the following factors should be applied: high tangential blade-speed $(U)$; high airflow axial-velocity $\left(C_{a}\right)$ and a high fluid deflection in the rotor blades $\left(\beta_{1}-\beta_{2}\right)$. It is worth noting that the pressure ratios generated by single stage fans for commercial aircraft turbo-fan engines are much higher than those of smaller Electrical Ducted Fans such as those used for manned and unmanned aircraft applications. This is primarily achieved, in the former, by generating very high tip speeds (e.g. $450 \mathrm{~m} / \mathrm{s}$ ) and utilising fan blades that are optimised for these resulting supersonic airspeeds relative to the outer portion of the fan blades [18]. Ducted fans offer improved efficiency, high exhaust-air speeds and lower noise when compared with open fans or propellers and are becoming increasingly popular for both manned and unmanned electrically powered aircraft $[25,26]$. Table 2 provides an indicative performance overview of a state of the art EDF which would typically be used to propel a small unmanned or radio-controlled aircraft. This EDF data is "generic" in nature and is not intended to represent any particular manufacturer's products and in this paper has been used for performance analysis purposes only.

The contribution of this paper is to the aerodynamic analyses of small rim-driven hub-less contra-rotating fan devices and to the discussion about their feasibility as propulsive devices to enable high-speed electrical flight.

The following analysis is presented in two main sections namely: Analysis Methodology (section II) and Computational Fluid Dynamic (CFD) Modelling (section III). Section II (Analysis Methodology) has four parts which are: A Generic EDF Analysis (part A); a Contra-Rotating Fan (RDF) Analysis (part B); a Blade Angles Determination (part C) and a determination of Fan Blade Profiles (part D). Section III (CFD modelling) provides a CFD analysis to 
validate the methodology of Section II. A final Section IV (Conclusion) provides a discussion and the conclusions made.

\section{Analysis Methodology}

Initially the analysis methodology was applied to a single stage fan device based on the generic EDF data from Table 2, and was conducted using a semi-empirical 2D "pitch line" calculation [27-29]. The results of this initial analysis are summarised in Table 3. This analysis methodology was then used to obtain the performance and size of the contra-rotating RDF assembly which is detailed in the subsequent section of this paper. Euler's principle relating to the rate of increase of angular momentum of a perfect (inviscid) fluid, between fan inlet and outlet, was applied in the initial 2D "pitch line" analyses based on the power exerted by the fan as defined by the following equation [30]:

$$
\mathbf{T} \omega=\int C_{w 2} \omega r_{2} d \dot{m}-\int C_{w 1} \omega r_{1} d \dot{m}
$$

In order to conduct these analyses some general assumptions, common to both the EDF and RDF, were made. It was assumed that the fans were operating under steady-state thrust conditions in International Standard Atmospheric (ISA) sea level static (freestream) conditions with: an inlet ambient temperature of $15^{\circ} \mathrm{C}(288 \mathrm{~K})$; air density of $\rho=1.225 \mathrm{~kg} / \mathrm{m}^{3}$ and static pressure $P=101325 \mathrm{~Pa}$.

A free vortex condition was also assumed, whereby the swirl velocity is inversely proportional to the radius position on the fan blade, and there is a constant absolute axial flow velocity $\mathrm{Ca}$ through the fan device. It has also been considered that the inlet and outlet fan tangential velocities are equal (i.e. $U_{1}=U_{2}$ ) and there is an increase in air density as it passes through the fan. Finally, CFD modelling of the contra-rotating RDF assembly using a "sliding mesh" technique was achieved using the fan blade architectures derived from these 2D calculations. The CFD model is described in section III and the results were considered to provide a more accurate account of RDF performance relating to airflow velocity and pressure profiles and distributions. 


\section{Table 2 Electrically Ducted Fan/Design Point}

Generic Specification

\begin{tabular}{lc}
\hline \hline Parameter & Value \\
\hline Thrust & $95 \mathrm{~N}$ \\
Exhaust Speed & $103 \mathrm{~m} / \mathrm{s}$ \\
Rotational Speed & $29,250 \mathrm{RPM}$ \\
Input Power (shaft) & $7.15 \mathrm{~kW}$ \\
Fan Swept Area & $82 \mathrm{~cm}$ \\
Inner Shroud Diameter & $120 \mathrm{~mm}$ \\
Hub Diameter & $40 \mathrm{~mm}$ \\
Motor Diameter & $63 \mathrm{~mm}$ \\
Overall Efficiency $\left(\eta_{o}\right)$ & $70.5 \%$ \\
\hline \hline
\end{tabular}

\section{A. Generic EDF Analysis}

Initially the mean diameter $\left(D_{m}\right)$ of the annulus was calculated which then allowed the Tangential Velocity $(U)$ of the fan blades at the mean diameter to be determined:

$$
\begin{gathered}
\mathrm{D}_{m}=\frac{\mathrm{D}_{\text {outer }}+\mathrm{D}_{\text {inner }}}{2} \\
U=\frac{\pi N \mathrm{D}_{m}}{60}
\end{gathered}
$$

Then the mass-flow $(\dot{m})$ of the air passing through the EDF was calculated for the maximum thrust under static conditions. Under the specified conditions (Table 2) the EDF is considered to be operating as a steady-flow system. Euler's principle of angular momentum can be applied to the flow through the fan rotor to establish the difference between the angular velocity at the mean diameter and hence the whirl velocity difference $\Delta C_{W}$ between the fluid entering and leaving the EDF.

$$
\begin{gathered}
\dot{m}=\frac{\text { Thrust }}{\left(V_{2}-V_{1}\right)} \\
\Delta C_{W}=\frac{\mathbf{P}}{\dot{m} U}
\end{gathered}
$$

Fan Pressure Ratio (FPR) is the ratio of the total pressure at the fan outlet to that at its inlet and has been calculated assuming a general isentropic efficiency value $\left(\eta_{s}\right)$ of 0.85 . The isentropic efficiency provides an indication of the amount of work that is usefully employed in raising the pressure to that which is dissipated in friction. Once the FPR is established the actual difference in pressure generated by the fan can be calculated and then a value for the Specific Work $(Y)$ can then be determined. 


$$
\begin{gathered}
F P R=\frac{P_{\text {Tout }}}{P_{\text {Tin }}}=\left(1+\eta_{s} \frac{U \Delta C_{w}}{C_{p} T_{o}}\right)^{\frac{\gamma}{(\gamma-1)}} \\
\Delta P_{T}=\left(F P R \times P_{\text {Tin }}\right)-P_{\text {Tin }} \\
Y=\frac{\Delta P_{T}}{\rho_{1}}
\end{gathered}
$$

The rise in pressure across the fan will be accompanied by a temperature rise in the air and changes in its density. The following formulae were used to provide values for the actual temperature rise and the mean air density through the fan. On establishing the mean air density an average value of volumetric flowrate through the fan was then calculated:

$$
\begin{gathered}
\Delta T_{\text {Actual }}=\frac{Y}{C_{p}} \\
\rho_{m}=\frac{P_{m}}{\mathbf{R} T} \\
\dot{V}=\frac{\dot{m}}{\rho_{m}}
\end{gathered}
$$

The value of input power from Table $2(7.15 \mathrm{~kW})$ was compared with the value calculated using the equation below as a "validity check" for the chosen methodology and the difference provided a minimal error of $-0.4 \%$.

$$
\text { Input Power }\left(\mathbf{P}_{\text {in }}\right)=\frac{C_{p} \times \Delta T}{\eta_{\text {overall }}}
$$

In the absence of outlet guide vanes, the resulting swirl element in the exhaust air from a single stage fan has the effect of reducing its maximum obtainable thrust. This has been determined in terms of a fan swirl parameter " $K$ " based on a "free vortex" swirl distribution. The swirl power in the exhaust air was calculated using the following formula:

$$
\mathbf{P}_{\text {swirl }}=\frac{\dot{m} K^{2}}{A_{2}}
$$

where,

$$
K=\frac{\mathbf{T}}{\dot{m}}
$$

and,

$$
\mathbf{T}=\text { Shaft Torque }=\frac{\mathbf{P}_{\text {shaft }} \times 60}{2 \times \pi \times N}
$$


This indicated that without outlet guide vanes the percentage power lost in swirl effects would be $7.1 \%$. However, the generic fan data of Table 2 has been derived from EDF units with outlet guide vanes installed. Their effectiveness was evaluated in terms of percentage power loss by calculating the rate and direction of kinetic energy transfer from the fan to the airflow, which resulted in a percentage of total power dissipated (lost) in swirl with outlet guide vanes of $3.2 \%$.

The power exerted on the airflow by the fan is:

$$
\mathbf{P}_{f}=\dot{m} \times U \times \Delta C_{W}
$$

The power required to accelerate the air axially for thrust:

$$
\mathbf{P}_{a}=\frac{1}{2} \dot{m} C_{a}^{2}
$$

Swirl power loss calculated with outlet guide vanes installed:

$$
\mathbf{P}_{s}=\mathbf{P}_{f}-\mathbf{P}_{a}
$$

There are various factors to be considered when selecting the ideal fan or compressor geometry for an application. Common choices of wheels are radial, diagonal, axial and drum rotors. Fortunately, there already exists much guidance literature on this topic and a valuable aid often used in this selection process is the Cordier Graph shown in Fig. 2.

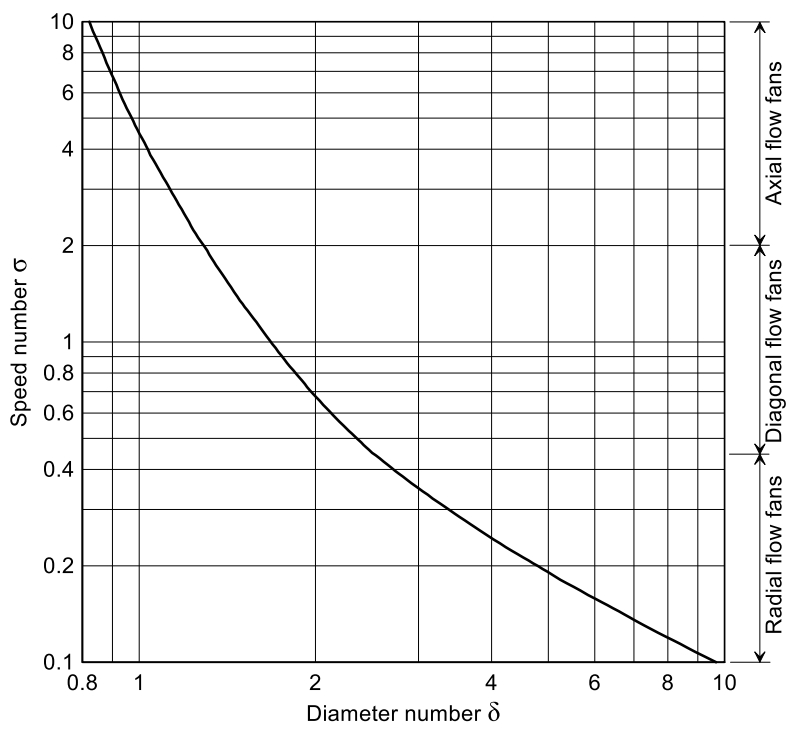

Fig. 2 Cordier Graph; data from [31].

The Cordier graph indicates optimum wheel types based on two important fan parameters calculated for the design point. Namely, the Fan Speed number $(\sigma)$ and the Fan Diameter number $(\delta)$. A theoretical derivation of these parameters and the associated Cordier graph can be found in the paper by Epple et al. [31]. The Fan Speed Number 
$(\sigma)$ is a dimensionless fan performance parameter based on the rotational speed of the fan, its volumetric through-flow and the specific work supply to the airflow.

$$
\sigma=N \frac{\sqrt{\dot{V}}}{\left(2 Y_{t}\right)^{\frac{3}{4}}} 2 \sqrt{\pi}
$$

Table 3 Generic EDF Analysis Results; derived from table 2 Input Data.

\begin{tabular}{lc}
\hline \hline Parameter Analysed & Calculated value \\
\hline Mean diameter $\left(D_{m}\right)$ & $91.5 \mathrm{~mm}$ \\
Tangential Velocity $(U)$ & $140.1 \mathrm{~m} / \mathrm{s}$ \\
Mass-flow $(\dot{m})$ & $0.992 \mathrm{~kg} / \mathrm{s}$ \\
Whirl velocity difference $\left(\Delta C_{W}\right)$ & $39 \mathrm{~m} / \mathrm{s}$ \\
Fan Pressure Ratio $($ FPR $)$ & 1.06 \\
Total Pressure Difference $\left(\Delta P_{t}\right)$ & $6080 \mathrm{~Pa}$ \\
Specific Work $(Y)$ & $4963.3 \mathrm{~kJ} / \mathrm{kg}$ \\
Temperature Rise $\left(\Delta T_{\text {Actual }}\right)$ & $5{ }^{\circ} \mathrm{C}$ \\
Mean air density $\left(\rho_{m}\right)$ & $1.263 \mathrm{~kg} / \mathrm{m}^{3}$ \\
Volumetric flowrate $(\dot{V})$ & $0.730 \mathrm{~m} / \mathrm{s}$ \\
Input Power $\left(\mathbf{P}_{\text {in }}\right)$ & $7121 \mathrm{~W}$ \\
Swirl power $\left(\mathbf{P}_{s w i r l}\right)$ & $357.4 \mathrm{~W}$ \\
Swirl parameter $(K)$ & $1.783 \mathrm{~m} / \mathrm{s}$ \\
Fan Shaft Torque $(T)$ & $1.644 \mathrm{Nm}$ \\
Power exerted on the airflow by the fan $\left(\mathbf{P}_{f}\right)$ & $5051 \mathrm{~W}$ \\
Power required to accelerate the air axially $\left(\mathbf{P}_{a}\right)$ & $4891 \mathrm{~W}$ \\
Swirl power loss $\left(\mathbf{P}_{s}\right)$ & $160 \mathrm{~W}$ \\
The Fan Speed Number $(\sigma)$ & 1.48 \\
The fan diameter Number $(\delta)$ & 1.24 \\
\hline \hline
\end{tabular}

The fan diameter number $(\delta)$ is also a dimensionless fan performance parameter but is based on the geometry of the fan its volumetric through flow and the specific work supply to the airflow.

$$
\delta=D \sqrt[4]{\frac{2 Y_{t}}{\dot{V}^{2}}} \times \frac{\sqrt{\pi}}{2}
$$

Reference to the Cordier graph (Fig. 2) indicates that the fan speed and diameter numbers place the optimum form, for this generic fan example, to be a diagonal, tending toward axial, fan type with a relatively high hub to fan diameter ratio. 


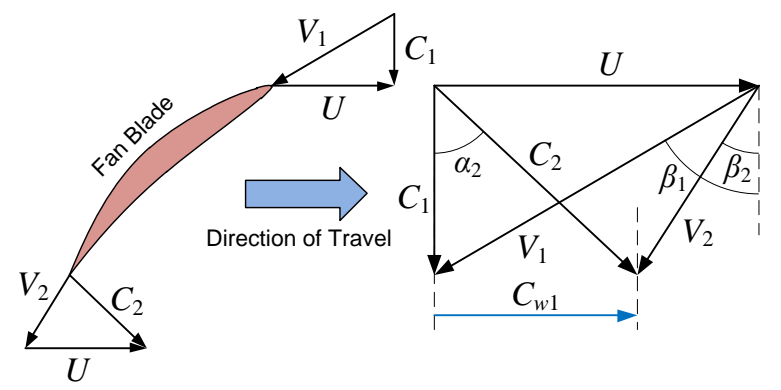

Fig. 3 Single-stage EDF Fan "Speed Triangle".

In line with accepted practice in the analysis of airflow through rotating devices, speed-triangles have been generated to depict the magnitude and direction of the velocity vectors being analysed applicable to the mean fan blade radius. This is a two-dimensional flow analysis technique in which the velocity components of the airflow are being considered in the axial and the tangential (known as the "whirl velocity") directions only. This method is commonly employed in axial compressor analysis where blade root-to-tip radius differences are relatively small. As the tangential velocity $(U)$ of the blade has the same value at its inlet and outlet, the velocity triangles in Fig. 3, have been constructed on a common base. It is considered worth mentioning the importance of the speed of sound on the relative velocity $V_{1}$ and the effect that introducing a $C_{1}$ impingement angle $\alpha_{1}$ (which is $0^{\circ}$ in Fig. 3), using Inlet Guide Vanes (IGVs), has on decreasing the magnitude of the $V_{1}$ vector.

$$
V_{1}=\sqrt{U^{2}+C_{1}^{2}}
$$

The inlet angle of the relative velocity vector $V_{1}$ is denoted $\beta_{1}$ and was determined using the following relationship:

$$
\tan \beta_{1 m}=\frac{U_{m}}{C_{a}}
$$

The outlet angle of the relative velocity vector $V_{2}$ is denoted $\beta_{2}$ and was determined using the following relationship:

$$
\tan \beta_{2 m}=\frac{U_{m}-C_{w 2}}{C_{a}}
$$

Tabulated below (Table 4) are the results of the blade calculations: 
Table 4 Single-Rotor Fan Blade Air Angles (EDF)

\begin{tabular}{lccc}
\hline \hline Blade Position & Inlet Angle & Outlet Angle & $\begin{array}{c}\text { Deflection Angle } \\
\varepsilon=\beta_{1}-\beta_{2}\end{array}$ \\
\hline Root & $\beta_{1 r}=43^{\circ}$ & $\beta_{2 r}=21^{\circ}$ & $\varepsilon=22^{\circ}$ \\
Mean & $\beta_{1 m}=53.7^{\circ}$ & $\beta_{2 m}=44.5^{\circ}$ & $\varepsilon=9.2^{\circ}$ \\
Tip & $\beta_{1 t}=61^{\circ}$ & $\beta_{2 t}=56^{\circ}$ & $\varepsilon=5^{\circ}$ \\
\hline \hline
\end{tabular}

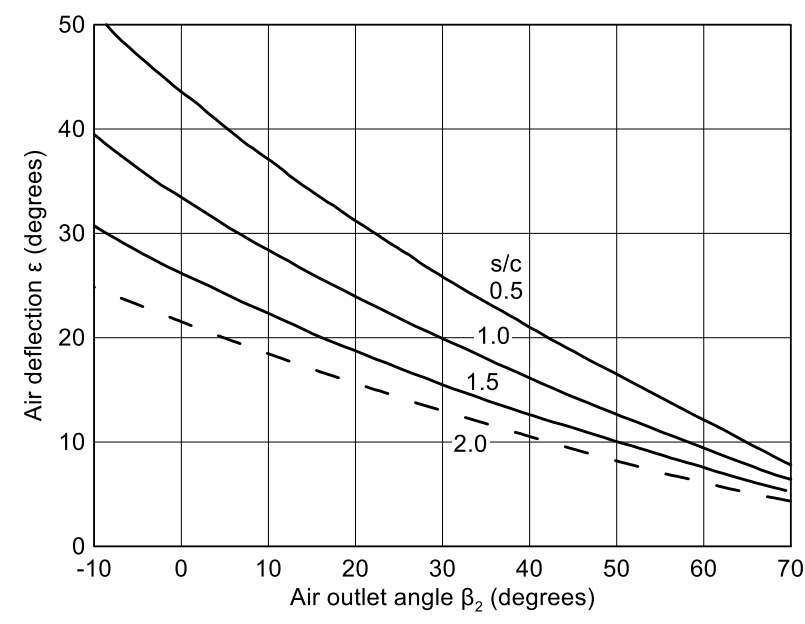

Fig. 4 Design deflection curves; data from [30].

The optimum number of annularly spaced fan blades has been determined by a semi-empirical analytical technique using Fig. 4 [24]. This set of master curves is a graphical representation of the results of a large number of tests conducted on different forms of blade cascades [32]. The nominal deflection angle $(\varepsilon)$ is plotted against the blade outlet angle $\left(\beta_{2}\right)$ with the pitch (spacing)/chord ratio (s/c) as a parameter. By way of example, for the mean radius position, the deflection angle is $10^{\circ}$ and the outlet angle $\beta_{2}$ is approximately $45^{\circ}$. From Fig. 4 the resulting value for the pitch (spacing) /chord ratio (s/c) $\approx 1.7$.

The aspect ratio for the blade height/chord $(h / c)$ was also selected from empirical and experiential results to be most effective at approximately $h / c=3.0$. The blade height at the mean radius position of the generic EDF $h_{m}$ then becomes:

$$
h_{m}=\frac{\operatorname{Rim} \text { Dia } \cdot-\text { Hub Dia } .}{2}
$$

The chord length at the mean radius position of the generic EDF $c_{m}$ then becomes:

$$
c_{m}=\frac{h_{m}}{3}
$$


The pitch (spacing) of the fan blades $s$ and number of blades $n$ are determined as:

$$
\begin{gathered}
s=c_{m} \times 1.7 \\
n=\frac{2 \pi r_{m}}{s}
\end{gathered}
$$

The results of the above EDF rotor dimensional analysis have been summarised below in Table 5 .

Table 5 Single-Rotor Fan Dimensions (EDF)

\begin{tabular}{lc}
\hline Parameter Analysed & Calculated value \\
\hline Mean blade height $\left(h_{m}\right)$ & $40 \mathrm{~mm}$ \\
chord length at the mean radius position $\left(c_{m}\right)$ & $13.3 \mathrm{~mm}$ \\
pitch (spacing) of the fan blades $(s)$ & $23 \mathrm{~mm}$ \\
number of blades $(n)$ & 12 \\
\hline \hline
\end{tabular}

\section{B. Contra-Rotating Fan (RDF) Analysis}

Fan design literature postulates that contra-rotating fan stages can provide an increase in the pressure ratio and hence fan airspeed and thrust for a given inlet area [14]. Additionally, there are efficiency benefits from the exhaust swirl cancellation. For the purpose of the following contra-rotating fan analysis the axial air velocity through the fan has been considered constant and equal to the ambient airspeed $\left(C_{\mathrm{a}}=C_{1}=C_{4}=\right.$ constant $)$.

The following analysis has been conducted to provide an initial estimate of the fan pressure ratio (FPR), fan blade design, thrust and input power requirements of a hub less Rim Driven Fan intended to provide a relatively high-speed exhaust air velocity of approximately $150 \mathrm{~m} / \mathrm{s}$ (i.e. $540 \mathrm{kph}, 336 \mathrm{mph}$ or Mach 0.44 at ISA SL conditions). Using the following equation an initial estimate of $\mathrm{FPR}=1.145$ was established to provide an exhaust airspeed of $C_{a}=C_{4}=151.1 \mathrm{~m} / \mathrm{s}:$

$$
C_{4 R D F}=\left[\frac{2 \gamma}{1-\gamma} \mathbf{R} T_{o}\left\{\left(\frac{P_{2}}{P_{o}}\right)^{\frac{(\gamma-1)}{\gamma}}-1\right\}\right]^{\frac{1}{2}}
$$

To achieve an overall FPR of 1.145 would requires two equal stage pressure ratios of:

$$
F P R_{\text {STAGE }}=\sqrt{1.145}
$$

Under these conditions the total pressure rise and specific work across the first stage of the RDF were evaluated. The mean air density was then determined and values for the mass and volumetric airflows through the RDF were established (Table 6). 


$$
\dot{m}_{R D F}=A_{R D F} \times C_{4 R D F} \times \rho_{m}
$$

Table 6 Contra-rotating first-stage fan (RDF) Analysis Results

\begin{tabular}{lc}
\hline \hline Parameter Analysed & Calculated value \\
\hline Fan Pressure Ratio $($ FPR $)$ & 1.07 \\
Total Pressure Difference $\left(\Delta P_{t}\right)$ & $7092.75 \mathrm{~Pa}$ \\
Specific Work $(Y)$ & $5790 \mathrm{~kJ} / \mathrm{kg}$ \\
Temperature Rise $\left(\Delta T_{\text {Actual }}\right)$ & $5.8^{\circ} \mathrm{C}$ \\
Mean air density $\left(\rho_{m}\right)$ & $1.262 \mathrm{~kg} / \mathrm{m}^{3}$ \\
Mass flowrate $\left(\dot{m}_{R D F}\right)$ & $2.1 \mathrm{~kg} / \mathrm{s}$ \\
Volumetric flowrate $(\dot{V})$ & $0.730 \mathrm{~m}^{3} / \mathrm{s}$ \\
The Fan Speed Number $(\sigma)$ & 3.35 \\
The fan diameter number $(\delta)$ & 0.72 \\
\hline \hline
\end{tabular}

Reference to the Cordier graph (Fig. 2) indicates that the fan speed and diameter numbers, applicable to individual stages only, confirm that the optimum form for the RDF is a pure axial flow fan. It was assumed that the absolute velocity (speed and direction) of the air leaving the first stage (rotor 1) is equal to the absolute velocity of the air impinging on the second stage (rotor 2) i.e. $C_{2}=C_{3}$. Additionally, with reference to Fig. 5 , it can be seen that the vector component of the whirl velocity $\mathrm{C}_{\mathrm{w} 2}$ is in the negative direction and accounts for the whirl component reversal of $C_{w 1}$. The algebraic sum of the whirl components $\left(\Delta C_{w}=C_{w 1}+C_{w 2}\right)$ was used to calculate the power exerted by the rotors.

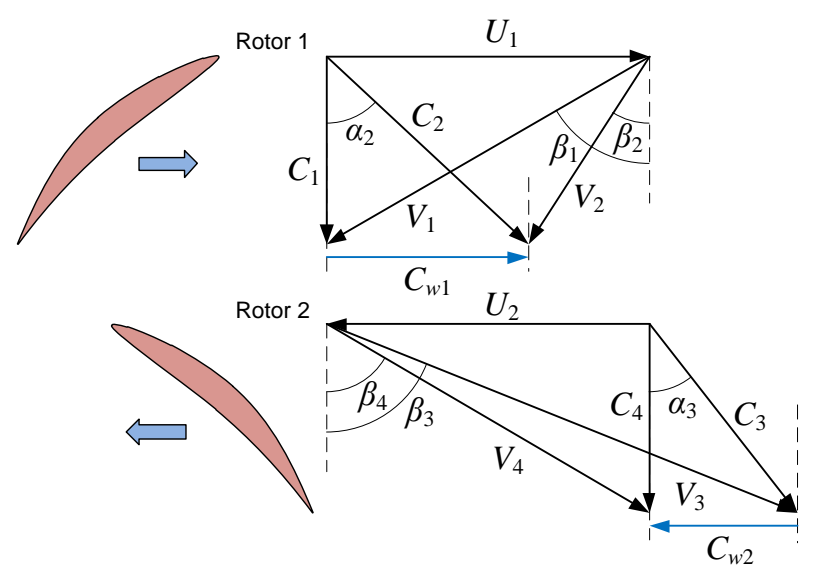

Fig. 5 Contra-rotating dual-stage RDF "Speed Triangle" Diagrams.

As with the generic EDF, the aspect ratio for the blade height/chord $(h / c)$ was selected at approximately $h / c=3.0$. Then: the blade height $h$ at the mean radius position $r_{m}$; the chord length at the mean radius position; the pitch (spacing) of the fan blades $s$ and the number of blades $n$ were calculated for the RDF, (Table 7): 


$$
r_{m}=\frac{\text { Tip rad } . \text { Hubless rad } \text {. }}{2}
$$

It was assumed that the removal of the exhaust swirl has the effect of "straightening" the exhaust airflow so that its velocity acts purely in the axial direction. This assumption allowed the following relationship to be developed enabling a total value of $\Delta C_{w}$ to be calculated based simply on axial airflow and fan blade tangential velocity values.

$$
\begin{gathered}
U=\omega r \\
\dot{m} U \Delta C_{W}=\frac{1}{2} \dot{m} v^{2} \\
\Delta C_{W}=\frac{v^{2}}{2 U}
\end{gathered}
$$

where the total value of whirl velocity is the sum of both rotor stages:

$$
\Delta C_{W}=\Delta C_{W 1}+\Delta C_{W 2}
$$

and the value for each stage was determined as:

$$
\Delta C_{W 1}=\Delta C_{W 2}
$$

If a value of isentropic efficiency of $85 \%$ is assigned [24], the following equation allows the contra-rotating fan stage pressure ratio and the change in the airflow whirl velocity to be checked.

$$
\frac{P_{2}}{P_{o}}=\left(1+\eta_{s} \frac{U \Delta C_{w}}{C_{p} T_{o}}\right)^{\frac{\gamma}{(\gamma-1)}}
$$

where $P_{o}$ is the total pressure at the inlet to the first fan stage and $P_{2}$ is the total pressure at the outlet of the second fan stage. The above pressure ratio equation can be used to calculate the overall fan pressure ratio when both rotors are operating at the same speed. The contra-rotating fan FPR value represents an increase of twice that of the single stage EDF previously analysed in this paper.

An estimate of the thrust and power requirements was then determined:

$$
\begin{gathered}
\text { Thrust }(R D F)=\dot{m}_{R D F} \times C_{4 R D F} \\
\text { Shaft Power }(R D F)=\dot{m}_{R D F} \times U \times \Delta C_{w} \\
\text { Input Power }=\frac{\text { Shaft Power }}{\eta_{o}}
\end{gathered}
$$

The RDF Rotor 1 inlet relative velocity vector $\left(V_{1}\right)$ was calculated as follows: 


$$
V_{1}=\sqrt{U_{m}^{2}+C_{a}^{2}}
$$

Table 7 Contra-rotating dual-stage RDF Parameters

\begin{tabular}{lc}
\hline \hline Parameter Analysed & Calculated value \\
\hline Absolute Axial Velocity $\left(C_{a}\right)$ & $151.1 \mathrm{~m} / \mathrm{s}$ \\
Mean blade height $\left(h_{m}\right)$ & $50 \mathrm{~mm}$ \\
Hub-less core diameter & $20 \mathrm{~mm}$ \\
Rim diameter & $120 \mathrm{~mm}$ \\
Hub to tip ratio & $20 / 120=0.167$ \\
Root radius & $10 \mathrm{~mm}$ \\
Mean radius position $\left(r_{m}\right)$ & $35 \mathrm{~mm}$ \\
Tip radius & $60 \mathrm{~mm}$ \\
Hub-less radius & $10 \mathrm{~mm}$ \\
Mean chord $\left(c_{m}\right)$ & $16.6 \mathrm{~mm}$ \\
Fan blade spacing $(s)$ & $28.2 \mathrm{~mm}$ \\
Number of fan blades $(n)$ & 8 \\
Swept area (annulus) & $110 \mathrm{~cm}$ \\
Tangential root velocity $\left(U_{\text {root }}\right)$ & $31 \mathrm{~m} / \mathrm{s}$ \\
Mean tangential velocity $\left(U_{\text {mean }}\right)$ & $107 \mathrm{~m} / \mathrm{s}$ \\
Tangential tip velocity $\left(U_{\text {tip }}\right)$ & $184 \mathrm{~m} / \mathrm{s}$ \\
Root whirl velocity difference $\left(\Delta C_{W 1 \text { root }}\right)$ & $61.2 \mathrm{~m} / \mathrm{s}$ \\
Mean whirl velocity difference $\left(\Delta C_{W 1 \text { mean }}\right)$ & $53.24 \mathrm{~m} / \mathrm{s}$ \\
Tip whirl velocity difference $\left(\Delta C_{W 1 \text { tip }}\right)$ & $30.6 \mathrm{~m} / \mathrm{s}$ \\
RDF pressure ratio $P_{2} / P_{o}$ & 1.122 \\
RDF Thrust & $317 \mathrm{~N}$ \\
RDF Shaft Power & $23971 \mathrm{~W}$ \\
RDF Input Power & $34001 \mathrm{~W}$ \\
Rotor 1 inlet relative velocity $\left(V_{1}\right)$ & $185.1 \mathrm{~m} / \mathrm{s}$ \\
Absolute velocities $\left(C_{2}=C_{3}\right)$ & $160 \mathrm{~m} / \mathrm{s}$ \\
Rotor 2 inlet relative velocity $\left(V_{3}\right)$ & $220 \mathrm{~m} / \mathrm{s}$ \\
Rotor 2 outlet relative velocity $\left(V_{4}\right)$ & $185.3 \mathrm{~m} / \mathrm{s}$ \\
\hline \hline
\end{tabular}

\section{RDF Blade Angles Determination}

Using derived trigonometric relationships, the magnitudes and directions of the absolute and relative air velocities were calculated for pitch line conditions at the fan blade root, mean and tip positions. The following tabulated equations (Table 8) have been provided to illustrate the methodology used and are applicable to the mean fan blade position. The RDF Rotor 2 fan blade inlet and outlet angles $\left(\beta_{3}\right.$ and $\left.\beta_{4}\right)$ were determined in a similar way as for Rotor 1 , where $C_{1}=151.1 \mathrm{~m} / \mathrm{s}$ and therefore: $C_{1}=C_{4}=151.1 \mathrm{~m} / \mathrm{s}$ and $C_{2}=C_{3}$. 
Table 8 Contra-rotating dual-stage RDF derived trigonometric relationships

\begin{tabular}{lc}
\hline \hline Parameter Description & Trigonometric Equation \\
\hline $\begin{array}{l}\text { The inlet angle of the relative velocity vector } V_{1} \\
\text { is denoted } \beta_{1} \text { and was determined using the } \\
\text { relationship: }\end{array}$ & $\tan \beta_{1 m}=\frac{U_{m}}{C_{a}}$ \\
$\begin{array}{l}\text { The outlet angle of the relative velocity vector } V_{2} \\
\text { is denoted } \beta_{2} \text { and was determined using the } \\
\text { relationship: }\end{array}$ & $\tan \beta_{2 m}=\frac{U_{m}-C_{w 2}}{C_{a}}$ \\
Absolute velocities $\left(C_{2}=C_{3}\right):$ & $C_{2}=C_{3}=\sqrt{C_{w 1}^{2}+C_{1}^{2}}$ \\
The air angle of the absolute velocities $\left(C_{2} \& C_{3}\right):$ & $\alpha_{2}=\alpha_{3}=\sin ^{-1} \frac{C_{w 1}}{C_{2}}$ \\
Rotor 2 inlet relative velocity $\left(V_{3}\right):$ & $V_{3}^{2}=C_{3}^{2}+U_{2}^{2}-2 C_{3} U_{2} \cos \left(\alpha_{3}+90^{\circ}\right)$ \\
RDF Rotor 2 fan blade relative velocity $V_{3}$ inlet \\
angle $\beta_{3}$ :
\end{tabular}

These derived trigonometric relationships were used to calculate the inlet and outlet blade angles for the first and second stage rotors of the RDF and the results have been tabulated below in Table 9 below.

Table 9 Contra-rotating Fan Blade Air Angles (RDF)

\begin{tabular}{lccc}
\hline \hline $\begin{array}{c}\text { Blade } \\
\text { Position }\end{array}$ & Inlet Angle & Outlet Angle & $\begin{array}{c}\text { Deflection Angle } \\
\varepsilon=\beta_{1}-\beta_{2}\end{array}$ \\
\hline Root & $\beta_{1 r}=11.2^{\circ}$ & Fan Rotor 1 & $\beta_{2 r}=-11.5^{\circ}$ \\
Mean & $\beta_{1 m}=35.3^{\circ}$ & $\beta_{2 m}=19.7^{\circ}$ & $\varepsilon=22.5^{\circ}$ \\
Tip & $\beta_{1 t}=49.9^{\circ}$ & $\beta_{2 t}=45.6^{\circ}$ & $\varepsilon=15.5^{\circ}$ \\
& & Fan Rotor 2 & \\
Root & $\beta_{3 r}=31.3^{\circ}$ & $\beta_{4 r}=11.5^{\circ}$ & $\varepsilon=19.8^{\circ}$ \\
Mean & $\beta_{3 m}=46.8^{\circ}$ & $\beta_{4 m}=35.3^{\circ}$ & $\varepsilon=10.8^{\circ}$ \\
Tip & $\beta_{3 t}=54.9^{\circ}$ & $\beta_{4 t}=50.8^{\circ}$ & $\varepsilon=4.1^{\circ}$ \\
\hline
\end{tabular}

This initial estimate of a hub-less contra-rotating fan arrangement, such as that of a Rim Driven Fan, suggests that a more than trebling of the fan static thrust rating could be achieved for the same fan (frontal) inlet area. However, this would be at a cost of more than quadrupling of the input power. Table 10 allows a comparison to be made with the Generic EDF analysed earlier in this paper. 
Table 10: Fan Comparison of the Design Point Generic Specification

\begin{tabular}{lcc}
\hline & EDF & RDF \\
\hline Thrust & $95 \mathrm{~N}$ & $317 \mathrm{~N}$ \\
Exhaust Speed & $103 \mathrm{~m} / \mathrm{s}$ & $151.1 \mathrm{~m} / \mathrm{s}$ \\
Rotational Speed & $29,250 \mathrm{RPM}$ & $29,250 \mathrm{RPM}$ \\
Input Power & $7.15 \mathrm{~kW}$ & $34 \mathrm{~kW}$ \\
Fan Swept Area & $82 \mathrm{~cm}^{2}$ & $110 \mathrm{~cm}^{2}$ \\
Inner Shroud Diameter & $120 \mathrm{~mm}$ & $120 \mathrm{~mm}$ \\
Motor Diameter & $63 \mathrm{~mm}$ & Not Applicable (RDF) \\
Overall Efficiency & $70 \%$ & $70 \%$ \\
\hline
\end{tabular}

\section{Fan Blade Profiles}

Fan blade profiles adopted by gas turbine engine manufacturers are proprietary in nature and not widely available in open literature. Such commercial blade designs have been developed to optimise flow patterns, strength characteristics, manufacturing advances and maintenance processes [33]. This study selected the NACA 65 series aerofoil profile $[34,35]$ which is aerodynamically similar to the RAF 27 profile and ' $\mathrm{C}$ series' that have been widely used in the UK for, subsonic axial flow, fan and compressor applications. The NACA 65 series promised good performance and its geometry and performance data are readily available in the public domain [36].

The symmetrical chord-line profile was modified based on a circular arc camber line. The radius of which is dependent on the subtended arc angle $\theta$ (Fig. 6) which is in turn determined from the inlet and outlet blade angles $\beta_{1}$ and $\beta_{2}$. NACA 65 series arc camber lines are denoted in terms of their associated design lift coefficient $\left(C_{L o}\right)$ of the aerofoil profile however, an approximate relation between the camber angle $\theta$ of circular arc aerofoils and the 65 series lift coefficient $\left(C_{L o}\right)$ can be obtained from the graph below (Fig. 7) [28].

In practice, although the airflow accurately follows the direction of the inlet blade angle $\left(\beta_{1}\right)$. It demonstrates a reluctance to turn through the full deflection of the blades resulting in a deviation $(\delta)$ from the outlet blade direction [24]. This deviation, which has also been taken into consideration in this analysis, depends mainly on the blade camber and pitch/chord ratio and can be estimated using the following empirically derived relationships:

$$
\delta^{\prime}=m \theta \sqrt{\frac{s}{c}}
$$

where,

$$
m=0.23\left(\frac{2 a}{c}\right)^{2}+0.1\left(\frac{\beta_{2}}{50}\right)
$$




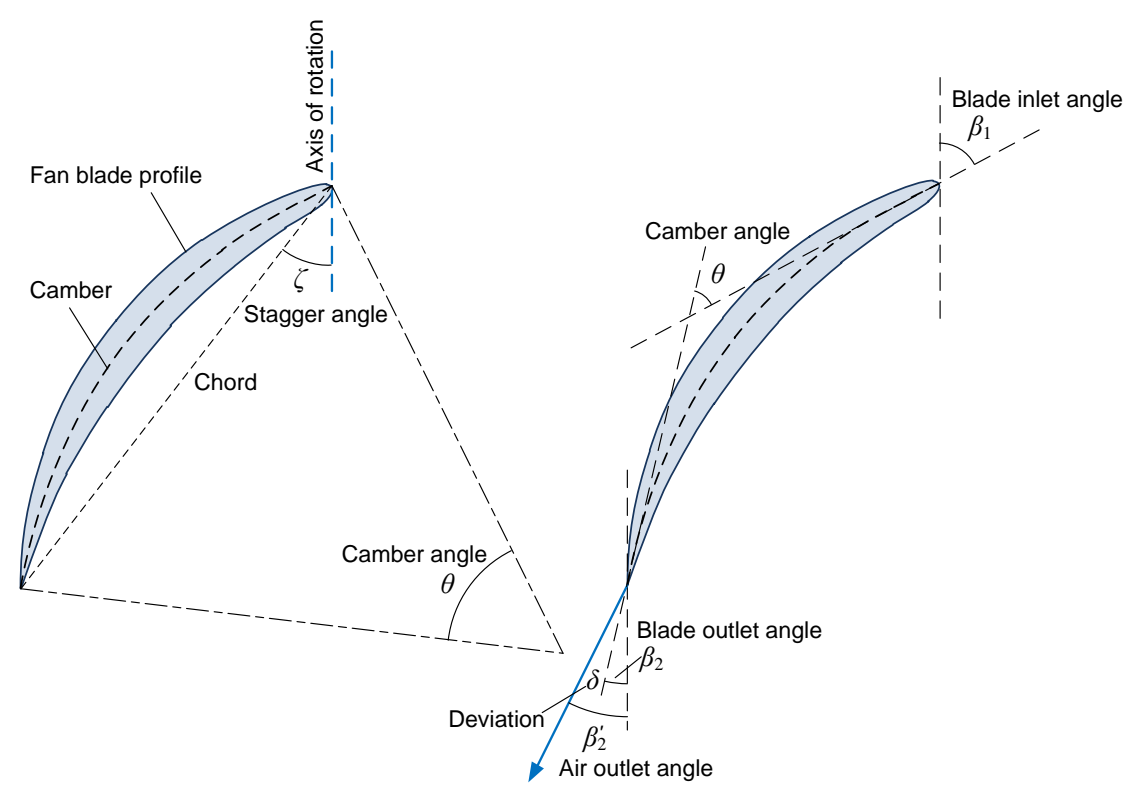

Fig. 6 NACA 65 Blade profile and annotation.

In the above equation " $a$ " is the distance to the point of maximum camber from the blade leading edge. Therefore, for the selected NACA 65 series circular arc camber line "a" occurs at the mid-point of the chord and the above term: $\left(\frac{2 a}{c}\right)^{2}=1$. And by way of example the deviation and stagger angles at the RDF rotor 1 mean fan blade radius was calculated as follows:

$$
\text { Deviation angle } \delta^{\prime}=\left[0.23+0.1 \times \frac{19.7}{50}\right] \sqrt{1.7} \times \theta=0.351 \theta
$$

Therefore, as: $\theta=\beta_{1}^{\prime}-\beta_{2}^{\prime}$ where $\beta_{1}^{\prime}=\beta_{1}$ (assuming zero incidence). Then the camber line arc angle was determined using:

$$
\begin{gathered}
\theta=\beta_{1}^{\prime}-\beta_{2}+\delta=\beta_{1}^{\prime}-\beta_{2}+0.351 \theta \\
0.649 \theta=\beta_{1}^{\prime}-\beta_{2}
\end{gathered}
$$

The outlet air angle was determined using:

$$
\beta_{2}^{\prime}=\beta_{1}^{\prime}-\theta
$$

The deviation angle was determined using:

$$
\delta^{\prime}=\beta_{2}-\beta_{2}^{\prime}
$$

The stagger angle $(\zeta)$ of the blade chord relative to the axial direction was then determined using the relationship: 


$$
\varsigma=\beta_{1}^{\prime}-\frac{\theta}{2}
$$

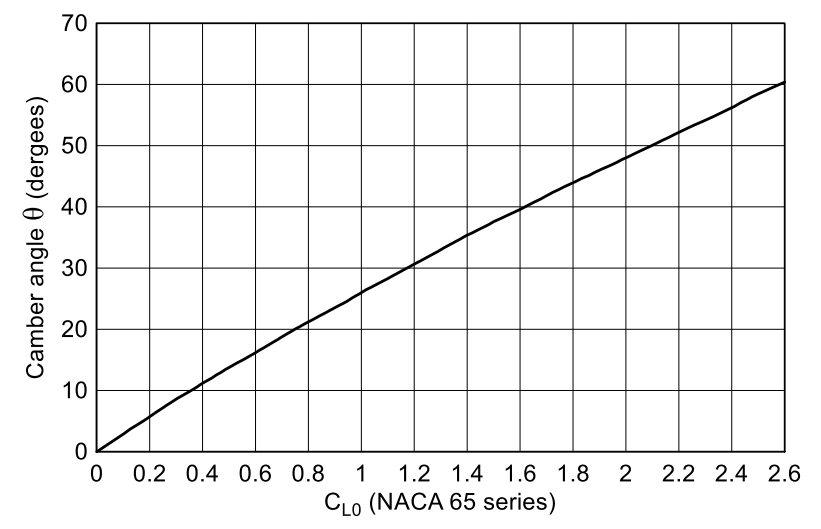

Fig. 7 NACA 65 series, approximate relation between $C_{L}$ and $\theta$ [28].

The Diffusion Factor $(\boldsymbol{D})$ indicates whether the fan blade air deflection values will incur excessive friction losses. Normally in the hub (root) region of a fan, losses are minimal and permit values of $\boldsymbol{D}$ up to 0.6. However, in the rotor rim (tip) region, losses become more significant whenever values of $\boldsymbol{D}$ exceed 0.4 [24]. The diffusion factors for varying rotor blade positions were calculated using the methodology illustrated by the following example, which is applicable to the mean radius position of rotor 1 :

$$
\boldsymbol{D} \approx 1-\frac{V_{2}}{V_{1}}+\frac{\Delta C_{w}}{2 V_{1}} \times \frac{s}{c}
$$

The camber arc radius was calculated using the following relationship:

$$
\text { Camber-arc Radius }=\frac{57.3}{\theta} \times c
$$

Table 11 Fan Rotor 1 - NACA Series 65 Aerofoil

\begin{tabular}{lccc}
\hline \hline & Root (Hub) & Mid & Tip (Rim) \\
\hline Chord Length $(c)$ & $5 \mathrm{~mm}$ & $16.6 \mathrm{~mm}$ & $29 \mathrm{~mm}$ \\
Stagger Angle $(\zeta)$ & $-4.4^{\circ}$ & $23.3^{\circ}$ & $46.2^{\circ}$ \\
Camber $(\theta)$ & $31.1^{\circ}$ & $24^{\circ}$ & $7.4^{\circ}$ \\
Deviation Angle $(\delta)$ & $8.4^{\circ}$ & $8.4^{\circ}$ & $3.1^{\circ}$ \\
Camber-arc Radius & $9.2 \mathrm{~mm}$ & $40 \mathrm{~mm}$ & $224.6 \mathrm{~mm}$ \\
Diffusion factor $(\boldsymbol{D})$ & 0.620 & 0.378 & 0.208 \\
\hline
\end{tabular}


Table 12 Fan Rotor 2 - NACA Series 65 Aerofoil

\begin{tabular}{lccc}
\hline \hline & Root $(\mathrm{Hub})$ & Mid & Tip (Rim) \\
\hline Chord Length $(c)$ & $5 \mathrm{~mm}$ & $16.6 \mathrm{~mm}$ & $29 \mathrm{~mm}$ \\
Stagger Angle $(\zeta)$ & $16.5^{\circ}$ & $37.5^{\circ}$ & $51.3^{\circ}$ \\
Camber $(\theta)$ & $29.6^{\circ}$ & $17.8^{\circ}$ & $7.2^{\circ}$ \\
Deviation Angle $(\delta)$ & $9.7^{\circ}$ & $7^{\circ}$ & $3.1^{\circ}$ \\
Camber-arc Radius & $9.7 \mathrm{~mm}$ & $53.8 \mathrm{~mm}$ & $230 \mathrm{~mm}$ \\
Diffusion factor $(\boldsymbol{D})$ & 0.581 & 0.589 & 0.338 \\
\hline
\end{tabular}

\section{Computational Fluid Dynamic (CFD) Modelling}

A solid model of the RDF fan assembly shown in Fig. 8 and 9 was constructed using the dimensions for the rotors 1 and 2, established in Tables 11 and 12.

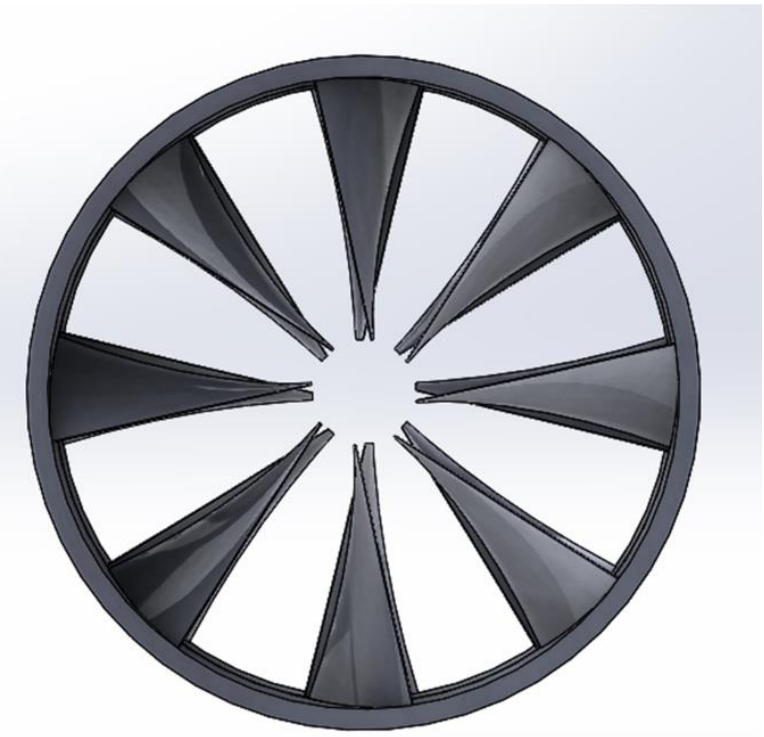

Fig. 8 An inlet view of the RDF solid model. 


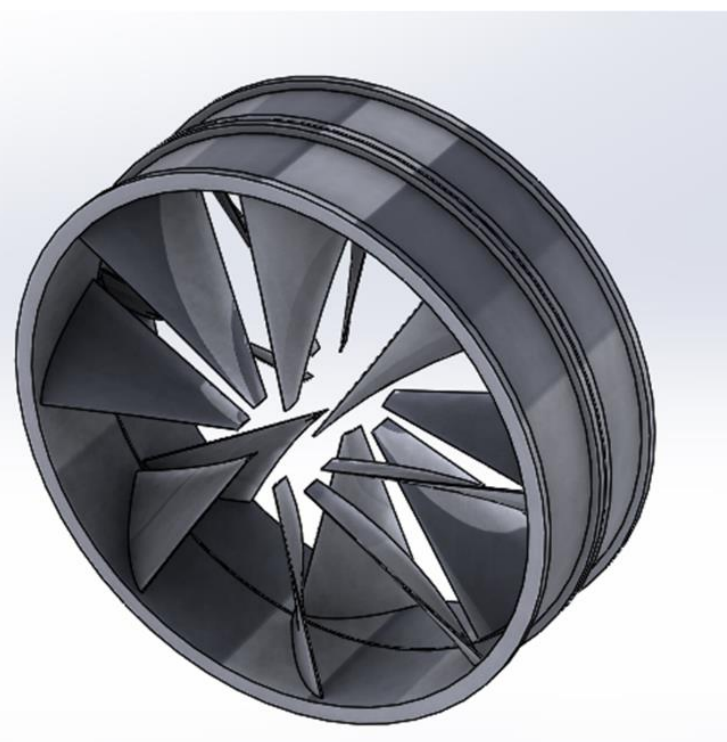

Fig. 9 An isometric view of the RDF solid model.

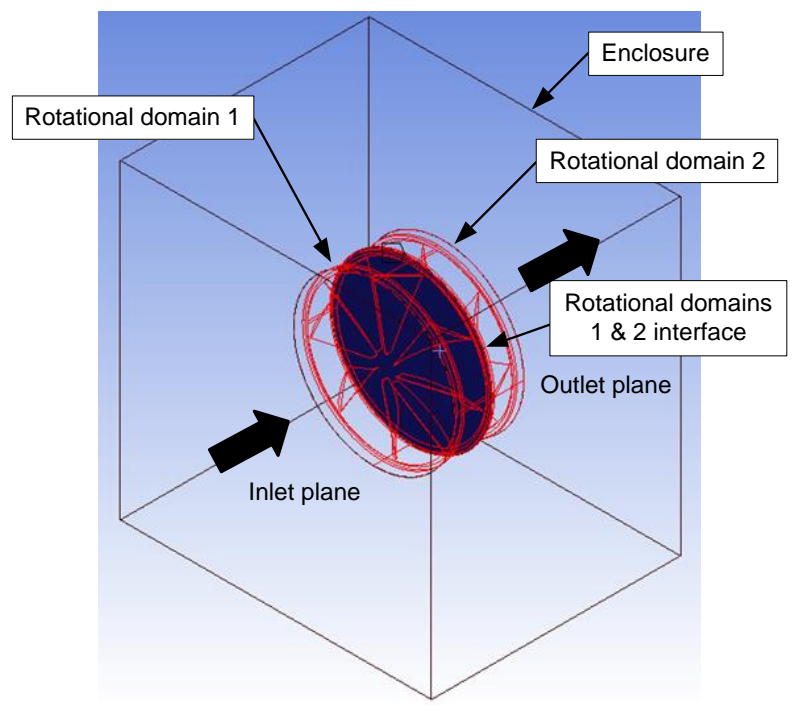

Fig. 10 Wireframe model of the RDF rotational domains and enclosure configuration

CFD modelling was conducted using ANSYS Fluent version 19.1. with a transient analysis of the RDF operation under static International Standard Atmospheric (ISA Sea Level) conditions. A dynamic, sliding-mesh model was generated, of two interfacing contra-rotational domains, representing RDF rotor 1 (cylinder diameter $=130 \mathrm{~mm}$, depth $\mathrm{Z}=30 \mathrm{~mm}$, comprising of 568,625 elements and 104,834 nodes) and rotor 2 (cylinder diameter $=130 \mathrm{~mm}$, depth $Z=25 \mathrm{~mm}$, comprising of 433,061 elements and 83,827 nodes) within a stationary cuboid enclosure $\mathrm{X}=250 \mathrm{~mm}$, $\mathrm{Y}=250 \mathrm{~mm}, \mathrm{Z}=200 \mathrm{~mm}$, comprising of 5217 elements and 1115 nodes (Fig. 10). The sliding-mesh is a special case 
of general dynamic mesh motion and allows the mesh zones, moving adjacent to one another, to link across nonconformal interfaces and the fluid to pass from one zone to another. The Cell Zone Conditions were configured to provide Mesh Motions, prescribing contra-rotational angular motion of the rotational domains, about their respective centers of gravity at 29,250 revolutions per minute (RPM). The "right-hand-rule" convention was assigned to denote their directions of rotation.

To model the turbulent compressible flow, Reynolds-Averaged Navier-Stokes (RANS) equations were solved. The following governing partial differential equations (PDEs) were used:

The mass continuity equation:

$$
\frac{\partial \rho}{\partial t}+\nabla^{T} \cdot(\rho \mathbf{u})=0
$$

$\mathrm{x}$-linear momentum equation:

$$
\frac{\partial(\rho U)}{\partial t}+\nabla^{T} \cdot(\rho U \mathbf{u})=-\frac{\partial P}{\partial x}+\nabla^{T} \cdot(\tau)-\frac{\partial\left(\overline{\rho u^{\prime 2}}\right)}{\partial x}-\frac{\partial\left(\overline{\rho u^{\prime} v^{\prime}}\right)}{\partial y}-\frac{\partial\left(\overline{\rho u^{\prime} w^{\prime}}\right)}{\partial z}
$$

y-linear momentum equation:

$$
\frac{\partial(\rho V)}{\partial t}+\nabla^{T} \cdot(\rho V \mathbf{u})=-\frac{\partial P}{\partial y}+\nabla^{T} \cdot(\tau)-\frac{\partial\left(\overline{\rho u^{\prime} v^{\prime}}\right)}{\partial x}-\frac{\partial\left(\overline{\rho v^{\prime 2}}\right)}{\partial y}-\frac{\partial\left(\overline{\rho v^{\prime} w^{\prime}}\right)}{\partial z}
$$

z-linear momentum equation:

$$
\frac{\partial(\rho W)}{\partial t}+\nabla^{T} \cdot(\rho W \mathbf{u})=-\frac{\partial P}{\partial z}+\nabla^{T} \cdot(\tau)-\frac{\partial\left(\overline{\rho u^{\prime} w^{\prime}}\right)}{\partial x}-\frac{\partial\left(\overline{\rho v^{\prime} w^{\prime}}\right)}{\partial y}-\frac{\partial\left(\overline{\rho w^{\prime 2}}\right)}{\partial z}
$$

The Energy Equation of the first law of thermodynamics:

$$
\begin{aligned}
& \frac{\partial}{\partial t}\left(\rho\left(e+\frac{1}{2} \mathbf{u}^{T} \cdot \mathbf{u}\right)\right)+\nabla^{T} \cdot\left(\rho \mathbf{u}\left(e+\frac{1}{2} \mathbf{u}^{T} \cdot \mathbf{u}\right)\right)= \\
& \quad-\nabla^{T} \cdot \mathbf{q}-\nabla^{T} \cdot(p \mathbf{u})+\nabla^{T} \cdot(\tau \cdot \mathbf{u})+\left(-\frac{\partial\left(\overline{\rho u^{\prime} e^{\prime}}\right)}{\partial x}-\frac{\partial\left(\overline{\rho v^{\prime} e^{\prime}}\right)}{\partial y}-\frac{\partial\left(\overline{\rho w^{\prime} e^{\prime}}\right)}{\partial z}\right)
\end{aligned}
$$

In the above equations (52-56):

$$
\tau=2 \mu\left(\frac{\nabla \mathbf{u}^{T}+\left(\nabla \mathbf{u}^{T}\right)^{T}}{2}-\frac{1}{3}\left(\nabla^{T} \cdot \mathbf{u}\right) \mathrm{I}\right)
$$


" $T$ " is the transpose, "I" is the identity matrix; the overbar signifies a time-averaged variable; $\mathbf{u}$ is the vector velocity of the air; $u, v$ and $w$ are the instantaneous velocity components of $\mathbf{u}$ in the $\mathrm{x}, \mathrm{y}$ and $\mathrm{z}$ directions respectively; $U, V$ and $W$ are the time-averaged components of the instantaneous velocity components $u, v, w$. And $u^{\prime}, v^{\prime}, w^{\prime}$ are the fluctuating components of, the instantaneous velocity components $u, v$ and $w$. For this analysis the body forces were considered negligible and therefore assumed to be zero.

A Realizable k-epsilon (k-€) turbulence model, with scalable wall functions, was used to model the Reynolds stresses and close the RANS equations. This involved the computation of two additional transport equations to determine the turbulence kinetic energy $(\mathrm{k})$ and the rate of dissipation $(\epsilon)$, of k per unit mass respectively:

$$
\frac{\partial}{\partial t}(\rho \mathrm{k})+\frac{\partial}{\partial x_{j}}\left(\rho \mathrm{k} u_{j}\right)=\frac{\partial}{\partial x_{j}}\left[\left(\mu+\frac{\mu_{t}}{\sigma_{k}}\right) \frac{\partial \mathrm{k}}{\partial x_{j}}\right]+G_{k}+G_{b}-\rho \varepsilon-Y_{M}+S_{k}
$$

and, $\quad \frac{\partial}{\partial t}(\rho \varepsilon)+\frac{\partial}{\partial x_{j}}\left(\rho \varepsilon u_{j}\right)=\frac{\partial}{\partial x_{j}}\left[\left(\mu+\frac{\mu_{t}}{\sigma_{\varepsilon}}\right) \frac{\delta \varepsilon}{\partial x_{j}}\right]+\rho C_{1} S \varepsilon-\rho C_{2} \frac{\varepsilon^{2}}{\mathrm{k}+\sqrt{v \varepsilon}}+C_{1 \varepsilon} \frac{\varepsilon}{\mathrm{k}} C_{3 \varepsilon} G_{b}+S_{\varepsilon}$

where, $C_{1}=\max \left[0.43, \frac{\eta}{\eta+5}\right], \eta=S \frac{\mathrm{k}}{\varepsilon}, S=\sqrt{2 S_{i j} S_{i j}}$

In the above equations, $G_{k}$ represents the generation of turbulence kinetic energy owing to the mean velocity gradients and $G_{b}$ is the generation of turbulence kinetic energy owing to buoyancy; $Y_{m}$ represents the contribution of the fluctuating dilation in compressible turbulence to the overall dissipation rate; $C_{2}=1.9$ and $C_{1 \varepsilon}=1.44$ are constants and $\sigma_{k}=1$ and $\sigma_{\varepsilon}=1.2$ are the turbulent Prandtl numbers for k and $\varepsilon$, respectively; $S_{k}$ and $S_{\varepsilon}$ are source terms.

The analysis assumes the air to behave as a Newtonian fluid with viscous stresses directly proportional to the rates of deformation and also to be isotropic and in thermodynamic equilibrium. The following constitutive laws relating to the state of a perfect gas were used to relate the variables pressure $(p)$ and internal energy $(i)$ with the two state variables of density $(\rho)$ and temperature $(T)$, (where: $\left.\mathbf{R}=C_{p}-C_{v}\right)$ :

$$
\begin{gathered}
p=\rho \mathbf{R} T \\
i=C_{v} T
\end{gathered}
$$

Sutherland's Viscosity Law was used to relate the temperature dependence of the air viscosity:

$$
\mu=\frac{C_{1} T^{3 / 2}}{T+C_{2}}
$$


where $\mu$ is the dynamic viscosity $(\mathrm{kg} / \mathrm{m} \cdot \mathrm{s}) ; T$ is the static temperature (K); co-efficient $C_{1}=1.458 \times 10^{-6} \mathrm{~kg} / \mathrm{m} \cdot \mathrm{s} ;$ coefficient $C_{2}=110.4 \mathrm{~K}$. Sutherland's Law was also used to calculate the thermal conductivity $(\boldsymbol{k})$ of the air:

$$
\boldsymbol{k}=\frac{C_{3} T^{3 / 2}}{T+C_{4}}
$$

where $\boldsymbol{k}$ is the coefficient of thermal conductivity $(\mathrm{W} / \mathrm{m} \cdot \mathrm{K}) ; T$ is the static temperature $(\mathrm{K})$; co-efficient $C_{3}=2.495 \times 10^{-3} \mathrm{~kg} \cdot \mathrm{m} / \mathrm{s}^{3} \mathrm{~K}^{3 / 2}$; co-efficient $C_{4}=194 \mathrm{~K}$. Once $\boldsymbol{k}$ was known, the following equation could be used to determine the thermal diffusivity of the air $\alpha\left(\mathrm{m}^{2} / \mathrm{s}\right)$ :

$$
\alpha=\frac{\boldsymbol{k}}{\rho C_{p}}
$$

The initial conditions applied everywhere in the solution region were: a temperature of $288 \mathrm{~K}$; an air-velocity (u) of $0 \mathrm{~m} / \mathrm{s}$; a dynamic viscosity of air $\mu=1.789 \times 10^{-5} \mathrm{~kg} / \mathrm{m} \cdot \mathrm{s}$; an air density $\rho=1.225 \mathrm{~kg} / \mathrm{m}^{3}$; and an air pressure of 0 Gauge (101325 Pa absolute). For the boundary conditions, a Pressure-Inlet boundary condition was applied at the inlet plane and a Pressure-Outlet boundary at the outlet plane refer to Fig. 10. All of the other boundaries, i.e. the enclosure surfaces and fan blades, were considered as wall boundaries. At the wall boundaries, no-slip and standard roughness conditions were applied and scalable wall functions were specified in order to maintain the near-wall grid nodes within the log-law region for flow analysis.

A global measure of discretisation error-estimate of the RDF mass-flow parameter was performed for the CFD model using multiple refined spatial grids of the enclosure and rotational domains. A posteriori error estimation procedure was used to determine that the actual order of convergence was 1.73. The difference between this actual (achieved) convergence value and the nominal order of convergence value of 2, being attributable, most likely, to turbulence and perhaps other factors such as grid stretching. Calculation of the grid convergence indices was performed and subsequently used to determine whether the solutions were in the asymptotic range of convergence, resulting in a value of 1.005148 . This value was considered to approximate to one, thus indicating that the solutions were within the asymptotic range of convergence. The grid convergence index for the fine grid was calculated to be $0.278 \%$ and the Richardson extrapolation method [37-39] was applied, using the values of the two finest grids, to estimate the RDF mass-flow at zero grid spacing. This was determined to be $1.414 \mathrm{~kg} / \mathrm{s}$ within an error band of $0.3 \%$. Fig. 11 shows a log-log plot of the RDF mass-flow parameter error-measure $\epsilon(\rho A v)$ decreasing as a function of the refined mesh size $\left(h_{m}\right)$. 


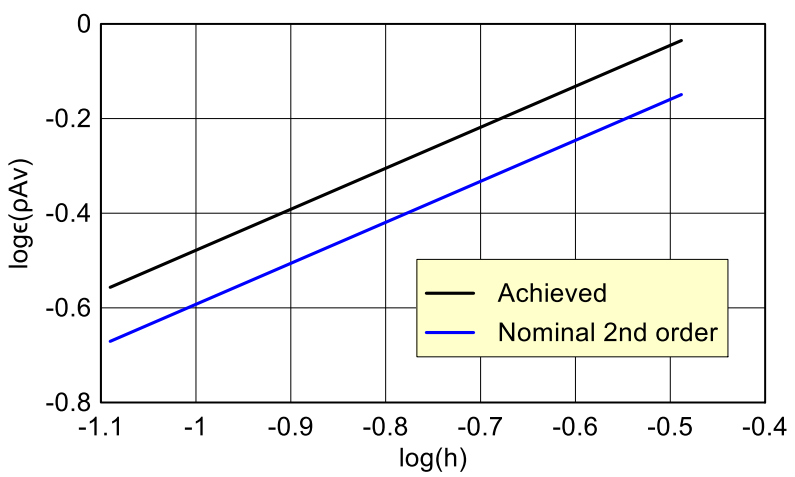

Fig. 11 Global Measure of the Discretisation Error (€) for the RDF Massflow ( $\rho A v)$

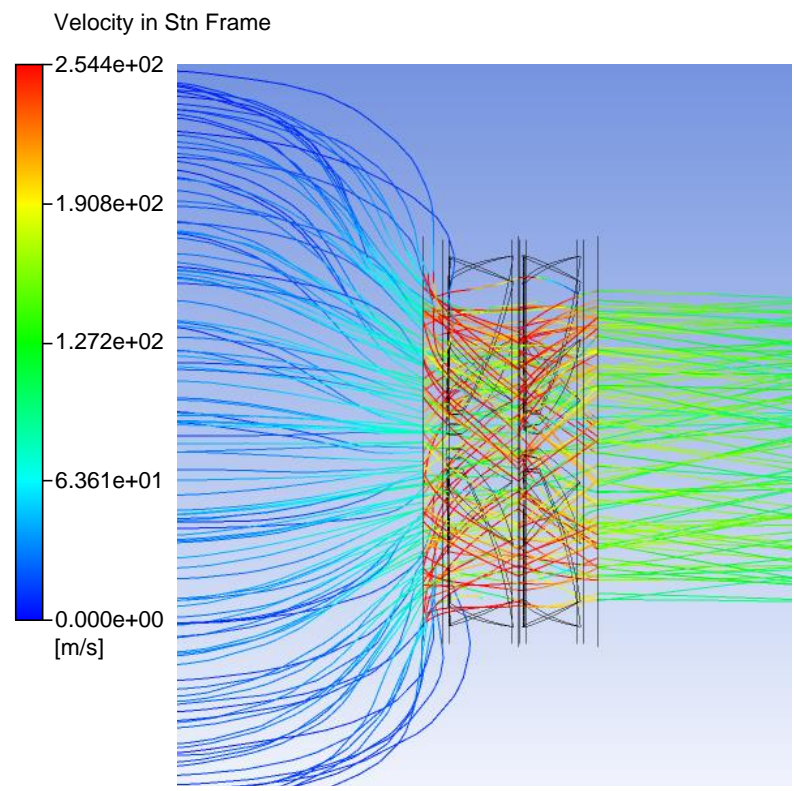

Fig. 12 Streamline image of the RDF operating at 29250 RPM. 


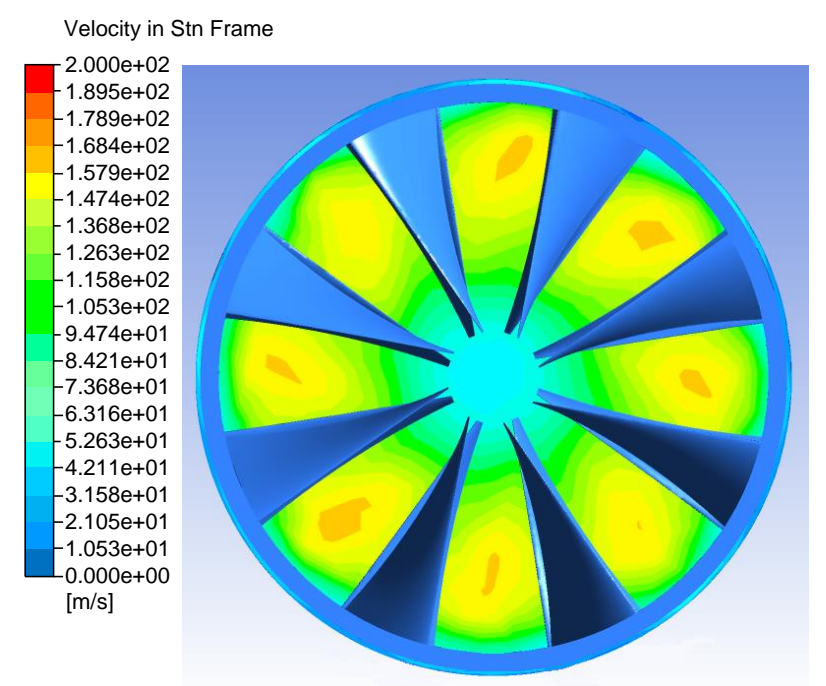

Fig. 13 Absolute velocity contours at the exit plane of rotor 2, operating at 29250 RPM.

Figure 12 shows a stream-line view of the results of the simulated RDF operating at 29,250 RPM under static thrust conditions. The forward fan being denoted rotor 1 and the aft fan rotor 2 . The side view of the velocity streamlines shows that there is minimal swirl in the fan efflux. This is an indication that the RDF is an efficient propulsive device and is attributable to the effects of the contra-rotating fans. Also visible in Fig. 12 are the stream-lines representing the airflows across the fan blades in the rotating fan domains. The streamlines indicate the presence of sub-sonic airflow velocities up to and in excess $200 \mathrm{~m} / \mathrm{s}$ and as such, these results correlate well with the 2D "pitch line" calculated mean values of airflow velocities: $V_{1}=185.1 \mathrm{~m} / \mathrm{s}, V_{2}=160.5 \mathrm{~m} / \mathrm{s}, V_{3}=221 \mathrm{~m} / \mathrm{s}$ and $V_{4}=185.3 \mathrm{~m} / \mathrm{s}$.

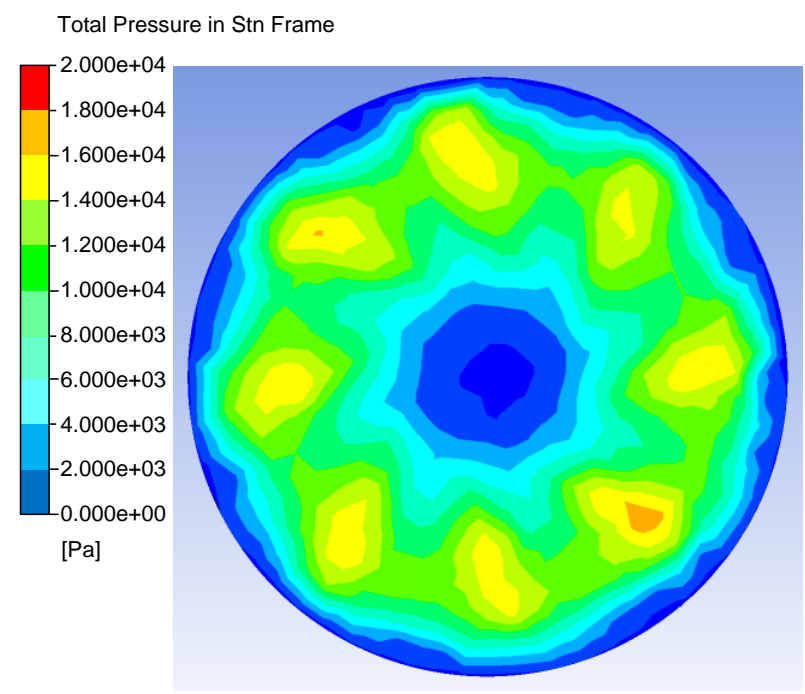

Fig. 14 Total pressure contours at the exit plane of rotor 2 operating at 29250 RPM. 
Fig. 13 is a colour-coded contoured velocity representation of the airflow at the Rotor-2, X-Y exit plane, as viewed from the RDF inlet perspective. This image indicates that the majority of the airflow is exhausting from the RDF as a large annulus of high-speed airflow with a velocity in the region of $150 \mathrm{~m} / \mathrm{s}$. This result also correlates well with the 2D "pitch line" calculated mean value of absolute velocity $C_{4}=151.1 \mathrm{~m} / \mathrm{s}$. The annulus of high-speed air can be seen to surround a core of lower speed air, which reduces to approximately $50 \mathrm{~m} / \mathrm{s}$ in the centre of the hub-less RDF. It is considered that the viscous effects of the high-speed annulus airflow act to induce the inner core flow which considerably augments the total mass flow of air and hence the attainable thrust for a given fan inlet diameter.

Fig. 14 is a colour-coded contoured representation of the total pressure at the Rotor-2, X-Y exit plane, as viewed from the RDF outlet perspective. The peak pressure regions indicate that there is a total pressure increase in the region of $14.0 \mathrm{kPa}$. above the ambient inlet total pressure of $101.325 \mathrm{kPa}$.

These pressure peak regions equate to a peak Fan Pressure Ratio (FPR) value of: FPR $=1.138$ and as such provides good agreement with the 2D "pitch line" calculated mean value of: FPR $=P_{2} / P_{o}=1.122$.

Table 13 provides a comparison of the values calculated using the $2 \mathrm{D}$ "pitch-line" methodology and the results generated by the CFD model for rotors 1 and 2 .

\section{Table 13 RDF Calculated 2D values versus CFD model results}

\begin{tabular}{lcc}
\hline Parameter & 2D Pitch-line values & CFD model results \\
\hline Fan-rotor 1 torque $(\mathrm{Nm})$ & 3.931 & 3.7 \\
Fan-rotor 2 torque $(\mathrm{Nm})$ & -3.931 & -3.92 \\
RDF net (reaction) torque $(\mathrm{Nm})$ & 0 & -0.22 \\
RDF Total torque $(\mathrm{Nm})$ & 7.826 & 7.599 \\
Rotational Speed $(\mathrm{RPM})$ & 29250 & 29250 \\
Angular velocity $(\mathrm{rad} / \mathrm{s})$ & 3063 & 3063 \\
RDF shaft power $(\mathrm{W})$ & 23,971 & 23,279 \\
Fan Pressure Ratio & $1.122($ mean $)$ & $1.138(\mathrm{peak})$ \\
Exhaust air velocity $(\mathrm{m} / \mathrm{s})$ & 151.1 & $\approx 150$ \\
Thrust $(\mathrm{N})$ & 317 & $\approx 212$ \\
\hline
\end{tabular}

\section{Conclusion}

The aerodynamic analysis of a small, multi-stage, Rim Driven Fan to enable high-speed electrically powered flight has been carried out. The results indicate that the, innovative two stage contra-rotating, RDF configuration provides the potential for a significant increase in the available thrust for a given fan inlet diameter and rotational speed. When compared with the dimensionally equivalent EDF technology, the thrust calculated (CFD results) for the RDF $=212 \mathrm{~N}$ 
and the EDF $=95 \mathrm{~N}$ with an accompanying RDF efflux velocity (CFD results) exceeding $150 \mathrm{~m} / \mathrm{s}$ (336 mph), whilst the efflux of the EDF $=103 \mathrm{~m} / \mathrm{s}(230 \mathrm{mph})$.

The velocity parameters calculated using the 2D pitch-line methodology accurately corresponded with the Ansys CFD results (refer to Table 13) and provided a fast and effective technique, prior to conducting detailed CFD analysis, with which to determine initial fan blade geometries and velocity estimates. However, the derived thrust values differed substantially between the 2D pitch-line methodology $(317 \mathrm{~N})$ and that of the CFD model $(212 \mathrm{~N})$. This was attributed mainly to an overly optimistic assumption of the effective fan through-flow area of the hub-less configuration that was used in the 2D pitch-line methodology. Although, it was also acknowledged that the velocity profile across the fan exit plane reduces dramatically from the fan blade root/rim $(\approx 180 \mathrm{~m} / \mathrm{s})$ to the centre $(\approx 50 \mathrm{~m} / \mathrm{s})$ and as a result the mean flow velocity parameter also reduces. Future adoptions of the $2 \mathrm{D}$ "pitch-line" calculation methodology may therefore benefit from CFD derived flow restriction coefficients. The CFD results demonstrated that although much whirl-cancellation had taken place through the RDF, the exhaust airflow still had a small degree of swirl present. This was also confirmed by the CFD value of $-0.22 \mathrm{Nm}$ net (reaction) torque on the RDF. It is considered that this net torque could be reduced to zero if differential speed control, providing active "speedtrimming", between the two independent rotors was implemented. This analysis has also confirmed that the highest air velocity $\left(V_{3}\right)$ is present at the inlet of the RDF rotor 2, and therefore may be considered a limiting parameter for sub-sonic fan designs.

Future studies are planned to analyze: the central core aerodynamics and the effects of blade tip vortices shedding; the resonance and acoustic signatures between rotors; differential speed control in order to balance the division of "reaction" 50\%-50\% (Stage Loading) between the rotor stages, and the design of a suitable air intake (diffuser) and exhaust nozzle to maximise the inlet pressure recovery and exhaust airspeed of the RDF. Although this analysis was conducted for an RDF device having a relatively small fan diameter of $120 \mathrm{~mm}$, the findings of this study can be equally applied to the performance of much larger and more powerful RDF propulsion units. Including RDF devices having multiple contra-rotating paired stages (e.g. 4, 6 or more rotors) in order to generate higher-pressure ratios and exhaust airspeeds suitable for large modern aircraft propulsion. 


\section{References}

[1] Graham, W.R., Hall, C.A., and Morales, M.V., "The Potential of Future Aircraft Technology for Noise and Pollutant Emissions Reduction,” Transport Policy, Vol. 34, 2014, pp. 36-51. https://doi.org/10.1016/j.tranpol.2014.02.017

[2] Masson, P.J., Brown, G.V., Soban, D.S., and Luongo C.A. "HTS Machines as Enabling Technology for All-electric Airborne Vehicles," Journal of Superconductor Science and Technology, Vol. 20, No. 8, 2007, pp. 748-756. https://doi.org/10.1088/0953-2048/20/8/005

[3] Viswanathan, V., and Knapp, B.M., "Potential for Electric Aircraft,” Nature Sustainability, Vol. 2, 2019, pp. 88-89. https://doi.org/10.1038/s41893-019-0233-2

[4] Madonna, V., Giangrande, P., and Galea, M., "Electrical Power Generation in Aircraft: Review, Challenges and Opportunities," IEEE Transactions on Transportation Electrification, Vol. 4, No. 3, 2018, pp. 646-659. https://doi.org/10.1109/TTE.2018.2834142

[5] Brelje, B.J., and Martins, J.R.R.A., "Electric, Hybrid, and Turboelectric Fixed-wing Aircraft: A Review of Concepts, Models, and Design Approaches,” Progress in Aerospace Sciences, Vol. 104, Jan. 2019, pp. 1-19. https://doi.org/10.1016/j.paerosci.2018.06.004

[6] Kim, H.D., Felder, J.L., Tong, M.T., Berton, J.J., and Haller, W.J., "Turboelectric Distributed Propulsion Benefits on the N3-X Vehicle," Aircraft Engineering and Aerospace Technology, Vol. 86, No. 6, 2014, pp. 558-561. https://doi.org/10.1108/AEAT-04-2014-0037

[7] Vratny, P.C., and Hornung, M., "Sizing Considerations of an Electric Ducted Fan for Hybrid Energy Aircraft," Transportation Research Procedia, Vol. 29, 2018, pp. 410-426. https://doi.org/10.1016/j.trpro.2018.02.037

[8] Pflimlin, J.-M., Binetti, P., Soueres, P., Hamel, T., and Trouchet, D., "Modeling and Attitude Control Analysis of a Ductedfan Micro Aerial Vehicle," Control Engineering Practice, Vol. 18, No. 3, 2010, pp. 209-218. https://doi.org/10.1016/j.conengprac.2009.09.009

[9] Bolam, R., and Vagapov. Y., "Implementation of Electrical Rim Driven Fan Technology to Small Unmanned Aircraft," 7th Int. Conf. on Internet Technologies and Applications ITA-17, Wrexham, UK, Sept. 2017, pp. 35-40. https://doi.org/10.1109/ITECHA.2017.8101907

[10] Propeller Theory, Curtiss-Wright Co., Caldwell, NJ, 1944.

[11] Hashimoto, F., Zhou, R., and Gradu, S.M., “Axial Flux Motor Assembly,” US Patent 6,922,004, 2005. 
[12] Chen, S.H., and Williams, M.H., "Panel Method for Counter-Rotating Propfans," Journal of Propulsion and Power, Vol 7. No. 4, 1991, pp. 593-601. https://doi.org/10.2514/3.23367

[13] Brouckaert, J.-F., Mirville, F., Phuah, K., and Taferner, P., “Clean Sky Research and Demonstration Programmes for Nextgeneration Aircraft Engines," The Aeronautical Journal, Vol. 122, No. 1254, 2018, pp. 1163-1175. https://doi.org/10.1017/aer.2018.37

[14] Guerin, S., Schnell, R., and Becker, R.G., "Performance Prediction and Progress Towards Multi-disciplinary Design of Contra-Rotating Open Rotors," The Aeronautical Journal, Vol. 118, No. 1208, 2014, pp. 1159-1179. https://doi.org/10.1017/S0001924000009830

[15] Eichenberg, D.J., Gallo, C.A., Solano, P.A., Thompson, W.K., and Vrnak, I.R., Development of a 32 inch Diameter Levitated Ducted Fan Conceptual Design, Rep. NASA/TM-2006-214481, NASA Glenn Research Center, Cleveland, 2006.

[16] Rolls Royce, The Jet Engine, 5th Edn., Wiley, Chichester, 2015.

[17] Nemnem, A.F., Zakaria, M.Y., and Elzahaby, A.M., "Contra-rotating Ducted Fan Aerothermodynamic Design Procedure for Unmanned Applications," 2018 AIAA Information Systems-AIAA Infotech and Aerospace AIAA, SciTech Forum, AIAA Paper 2018-0745, 2018. https://doi.org/10.2514/6.2018-0745

[18] Akturk, A., and Camci, C., "Experimental and Computational Assessment of a Ducted-fan Rotor Flow Model," Journal of Aircraft, Vol. 49, No. 3, 2012, pp. 885-897. https://doi.org/10.2514/1.C031562

[19] Mistry, C., and Pradeep, A.M., "Experimental Investigation of a High Aspect Ratio, Low Speed Contra-rotating Fan Stage with Complex Inflow Distortion,” Propulsion and Power Research, Vol. 3, No. 2, 2014, pp. 68-81. https://doi.org/10.1016/j.jppr.2014.05.005

[20] Chen, Y.Y., Liu, B., Xuan, Y., and Xiang, X.-R., “A Study of Speed Ratio Affecting the Performance of a Contra-rotating Axial Compressor," Proceedings of IMechE, Part G: Journal of Aerospace Engineering, Vol. 222, No. 7, 2008, pp. 985991.

https://doi.org/10.1243/09544100JAERO364

[21] Zhang, H., Huang, X., and Zhang, X., "Investigation of Unsteady Effects on a Two-stage Counter-rotating Fan," Procedia Engineering, Vol. 126, 2015, pp. 358-361.

https://doi.org/10.1016/j.proeng.2015.11.211 
[22] Nouri, H., Ravelet, F., Bakir, F., Sarraf, C., and Rey, R., "Design and Experimental Validation of a Ducted CounterRotating Axial-Flow Fans System,” Journal of Fluids Engineering, Vol. 134, No. 10, Article 104504, 2012. https://doi.org/10.1115/1.4007591

[23] Mistry, C., and Pradeep, A.M., "Effect of Variation in Axial Spacing and Rotor Speed Combinations on the Performance of a High Aspect Ratio Contra-rotating Axial Fan Stage," Proceedings of the Institution of Mechanical Engineers, Part A: Journal of Power and Energy, Vol. 227, No. 2, 2013, pp.138-146.

https://doi.org/10.1177/0957650912467453

[24] Saravanamuttoo, H.I.H., Rogers, G.F.C., Cohen, H., and Straznicky, P.V., Gas Turbine Theory, 6th Edn., Pearson Prentice Hall, Upper Saddle River, 2009.

[25] Johnson, E.N., and Turbe, M.A., "Modelling, Control, and Flight Testing of a Small Ducted-Fan Aircraft," Journal of Guidance, Control, and Dynamics, Vol. 29, No. 4, 2006, pp. 769-779.

https://doi.org/10.2514/1.16380

[26] Bontempo, R., and Manna, M., "Effects of Duct Cross Section Camber and Thickness on the Performance of Ducted Propulsion Systems for Aeronautical Applications," International Journal of Aerospace Engineering, Vol. 2016, Article ID 8913901.

https://doi.org/10.1155/2016/8913901

[27] Horlock, J.H., Axial Flow Compressors, Butterworths Scientific Publ., London, 1958.

[28] Turner, R.C., Notes on Ducted Fan Design. Current papers (Aeronautical Research Council (Great Britain)), no. 895, H.M.S.O, London, 1966.

[29] Johnsen, I.A., and Bullock, R.O., Aerodynamic Design of Axial-flow Compressors, NASA SP (Series), 36., NACA, Washington, 1965.

[30] Rogers, G., and Mayhew, Y., Engineering Thermodynamics: Work and Heat Transfer, 4th edn., Pearson: Harlow, 1992.

[31] Epple, Ph., Durst, F., and Delgado, A., “A Theoretical Derivation of the Cordier Diagram for Turbomachines,” Proceedings of IMechE, part C: Journal of Mechanical Engineering Science, Vol. 225, No. 2, 2011, pp. 354-368. https://doi.org/10.1243/09544062JMES2285

[32] Panchal, S., and Mayavanshi, V., "Experimental Study of Flow Through Compressor Cascade," Case Studies in Thermal Engineering, Vol. 10, Sept. 2017, pp. 234-243. https://doi.org/10.1016/j.csite.2017.05.002

[33] Amoo, L.M., "On the Design and Structural Analysis of Jet Engine Fan Blade Structures,” Progress in Aerospace Sciences, Vol. 60, July 2013, pp. 1-11. https://doi.org/10.1016/j.paerosci.2012.08.002 
[34] Castegnaro, S., "Effects of NACA 65-blade's Trailing Edge Modifications on the Performance of a Low-speed Tube-axial Fan,” Energy Procedia, Vol. 82, 2015, pp. 965-970.

https://doi.org/10.1016/j.egypro.2015.11.852

[35] Abbott, I.H., and von Doenhoff. A.E., Theory of Wing Sections, Dover Publications Inc., New York, 1959.

[36] Carter, A.D.S., "Blade Profiles for Axial-Flow Fans, Pumps, Compressors, etc.," Proceedings of IMechE, Vol. 175, No. 1. 1961, pp. 775-806.

https://doi.org/10.1243/PIME_PROC_1961_175_051_02

[37] Bonfiglioli, A., and Paciorri, R., "Convergence Analysis of Shock-Capturing and Shock-Fitting Solutions on Unstructured Grids,” AIAA Journal, Vol. 52, No. 7, 2014, pp. 1404-1416.

https://doi.org/10.2514/1.J052567

[38] Thomas, J. L., Diskin, B., and Rumsey, C. L., “Toward Verification of Unstructured-Grid Solvers,” AIAA Journal, Vol. 46, No. 12, 2008, pp. 2070-3079.

https://doi.org/10.2514/1.36655

[39] Roache, P.J., "Perspective: A Method for Uniform Reporting of Grid Refinement Studies," Journal of Fluids Engineering, Vol. 116, No. 3, 1994, pp. 405-413.

https://doi.org/10.1115/1.2910291 